\title{
Determination of the molecular signature of fossil conifers by experimental palaeochemotaxonomy - Part 1: The Araucariaceae family
}

\author{
Y. Lu, Y. Hautevelle, and R. Michels \\ UMR 7359 CNRS Georessources, University of Lorraine, BP 239, 54506 Vandœuvre-lès-Nancy cedex, France \\ Correspondence to: Y. Hautevelle (yann.hautevelle@univ-lorraine.fr)
}

Received: 11 July 2012 - Published in Biogeosciences Discuss.: 8 August 2012

Revised: 7 January 2013 - Accepted: 17 February 2013 - Published: 20 March 2013

\begin{abstract}
Twelve species of the conifer family Araucariaceae, including Araucaria (6 species), Agathis (3 species) and Wollemia (1 species) genera, were submitted to artificial maturation by confined pyrolysis. The aim of these experiments is to transform the biomolecules synthesized by these species into their homologous geomolecules in laboratory conditions. Determination of the diagenetic molecular signatures of Araucariaceae through experimentation on extant representatives allows us to complete our knowledge in botanical palaeochemotaxonomy. Such knowledge is relevant to palaeoenvironmental, environmental and archaeology purposes. All artificially diagenetic species of Araucariaceae are firstly characterized by a predominance of saturated tetracyclic diterpenoids including ent-beyerane, phyllocladanes and ent-kauranes. Moreover, Araucaria genus shows a high relative abundance of bicyclic sesquiterpenoids, particularly the cadalane-type compounds accompanied by those of eudesmane and bisabolane types as well as chamazulene and pentamethyl-dihydroindenes. Diterpenoids are of labdane, isopimarane and abietane types (essentially derived from abietanoic acids) as well as isohexyl alkylaromatic hydrocarbons. Compared to the tetracyclic diterpenoids, these compounds show a relatively lower abundance, reaching trace levels in the case of saturated abietanes. Distributions of sesquiterpenoids and diterpenoids of Agathis show some similarities to that of Araucaria, with the exception of one species, in which the tetracyclic compounds are absent and the abietane type (essentially derived from abietanoic acids) predominant. High similarities between the Wollemia and Araucaria genera are observed. Both are characterized by some high relative abundance of tetracyclic compounds with no predominance of other specific diterpenoids.
\end{abstract}

\section{Introduction}

Numerous studies of the molecular composition of extant terrestrial plants have pointed out the chemotaxonomic values of many biological compounds, bioterpenoids in particular (e.g. Aplin et al., 1963; Smith, 1976; Castro et al., 1996; Mongrand et al., 2001). This means that these biomolecules are synthesized by a restricted number of plant taxa and can be used as specific markers. While most bioterpenoids are degraded and their atomic constituents recycled in the surface processes of Earth, a minor part is incorporated into sediments, thus joining the geological cycle. During this process, the bioterpenoids are transformed by diagenesis, leading to the formation of reaction products called geoterpenoids. Their initial chemotaxonomic value can be partially or totally retained (e.g. Simoneit, 1986; Otto and Simoneit, 2001). Geoterpenoids of ancient sediments may thus provide palaeochemotaxonomic information inherited from their biological precursors.

Botanical palaeochemotaxonomy has some specific attributes compared to palaeobotany and palynology in the reconstruction of palaeofloral and palaeoclimatic evolutions through geological times (e.g. Vliex et al., 1994; van Aarssen et al., 2000; Hautevelle et al., 2006a). Indeed, (1) plant biomarkers are more widespread in the stratigraphic record than well-preserved plant macrofossils; (2) on the contrary to Palaeozoic and Mesozoic palynomorphs, they can be directly linked to specific taxa of plants, and (3) biomarkers could be readily analysed by usual organic geochemistry procedures on total rock samples.

In addition to being useful to palaeofloristic and palaeoclimatic studies, botanical palaeochemotaxonomy has also been recently applied in other instances. In environmental science, 
it proved to be helpful in the appreciation of past land use and recent anthropogenic impacts to soil (e.g, Farella et al., 2001; Heim et al., 2010; Huang et al., 2011; Lavrieux et al., 2011) as well as in tracing river pollution caused by paper mills (e.g. Leeming and Nichols, 1998; Wang at al., 2007). In archaeology, palaeochemotaxonomy is used to trace dietary habits and to understand the use of natural products in craft and funeral rites (e.g. Colombini et al., 2005; Romanus et al., 2008).

Most of palaeochemotaxonomic investigations are derived from published chemotaxonomic data (Otto and Wilde, 2001) and to some parts from the studies of fossil plants found in sedimentary rocks (Otto and Simoneit, 2001; Otto et al., 2005; Dutta et al., 2011). Unfortunately, our knowledge on botanical palaeochemotaxonomy is still very scarce. As pointed out by Hautevelle et al. (2006b), difficulties are related to the following: (1) available chemotaxonomic data (generally focused on specific biomolecules or on particular substances, like resins or essential oils); (2) degradation and diagenetic reactions, which may significantly modify the initial molecular fingerprint, making it difficult to perform a direct chemotaxonomic relationship between an extant plant and its fossil counterpart; (3) the scarcity of reference collections of well-preserved and identifiable fossil plants containing organic molecules.

In order to fill these gaps, within the 7 extant conifer families (Fig. 1), we investigated the palaeochemotaxonomy of several extant species of the Araucariaceae (Table 1) using an experimental method based on artificial maturation by confined pyrolysis (Hautevelle et al., 2006b). This procedure allows simulation of the conversion of biomolecules into their corresponding diagenetic geomolecules (Stankiewicz et al., 2000; Gupta et al., 2006, 2007). Aims of this study are (1) to determine the common palaeochemotaxonomic (diagenetic) signatures of all extant Araucariaceae species, (2) to evaluate the inter- and intra-generic differences within the family, (3) to highlight the molecular characteristics which should allow their distinction from other conifer families in ancient sediment samples. This contribution should serve as a database for future palaeoenviroennemental, archaeological and environmental research.

\section{Some generalities concerning the Araucariaceae family}

Araucariaceae is considered as a Southern Hemisphere conifer family and was among the first conifer families to be individualized from their "Voltziales" ancestors during the Triassic (Stockey, 1994). Diversity and abundance of Araucariaceae are well preserved up to present despite some reduction of geographic distribution and extinction of several species during evolution (Axsmith et al., 2004; Kunzmann, 2007a).

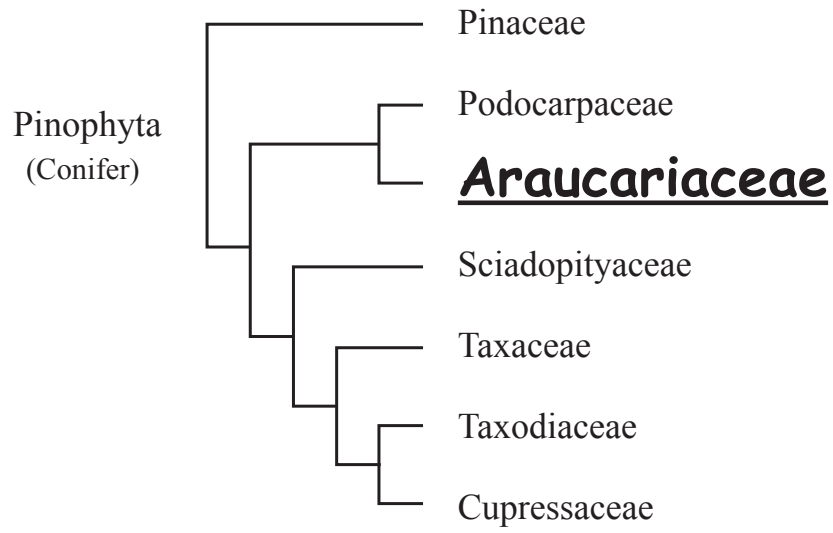

Fig. 1. Phylogenetic classification of conifers.

\subsection{Taxonomy, geographical distribution and living environments}

\subsubsection{Extant Araucariaceae}

Today, Araucariaceae species represent a dominant component of Southern Hemisphere forests. The major native Araucariaceae species are restricted to the South American, South-West Asian and the Western Pacific regions and cover a large rainfall region extending from subtropics to tropics (Enright and Hill, 1995). Nowadays, more than 40 species are described and consist of three well-defined genera, which are (1) Agathis (Salisbury, 1807), represented by 21 species, (2) Araucaria (Jussieu, 1978) represented by 19 species and (3) Wollemia (Jones et al., 1995) represented by the single species Wollemia nobilis. The latter, previously thought to be extinct, was rediscovered in 1994 in Australia, cloistered deep in the New South Wales (Jones et al., 1995).

These phylogenitic relationships of Araucariaceae species were also confirmed by Setoguchi et al. (1998) based on $r b c L$ gene sequences:

- the three genera are all monophyletic (i.e. all species descend from a unique ancestor);

- Araucaria could be intra-generically classified into four sections: Araucaria, Bunya, Eutacta, and Intermedia. This sub-classification is in agreement with their morphological characteristics (Stockey, 1982);

- phylogenetic relationships within Agathis remain somewhat unclear;

- Wollemia is the most basal extant taxon in the family, sharing morphologies with Araucaria and Agathis.

Geographic distribution of major Araucariaceae species is given in Table 1. Extant Araucaria species develop in the subtropical regions and extend into the marginal tropical regions where there is a lower climatic variability, while 
Table 1. Phylogentic relationships, geographical range and provenance of Araucariaceae species selected for this study.

\begin{tabular}{|c|c|c|c|c|}
\hline Genera & Section & Species & Geographical range & Sample's provenance \\
\hline \multirow{3}{*}{ Agathis } & & $\begin{array}{l}\text { australis (D. Don) Loudon (1829) } \\
\text { Syn. : Dammara australis, Podocarpus zamiifolius } \\
\text { Com. : kauri, New Zealand kauri }\end{array}$ & $\begin{array}{l}\text { New Zealand } \\
\text { (Northland \& Coromandel } \\
\text { peninsulas) }\end{array}$ & $\begin{array}{l}\text { Muséum National } \\
\text { d'Histoire Naturelle } \\
\text { (Paris, France) }\end{array}$ \\
\hline & & $\begin{array}{l}\text { moorei (Lindl.) Mast (1892) } \\
\text { Syn. : Dammara moorei, Dammara lanceolata } \\
\text { Com. : Moore kauri }\end{array}$ & New Caledonia & $\begin{array}{l}\text { Botanical Garden } \\
\text { of Lyon (France) }\end{array}$ \\
\hline & & $\begin{array}{l}\text { robusta (C. Moore ex F. Muell.) Bailey (1883) } \\
\text { Com. : Queensland kauri, smooth-bark kauri, kauri pine }\end{array}$ & $\begin{array}{l}\text { Australia } \\
\text { (Queensland) }\end{array}$ & $\begin{array}{l}\text { Botanical Garden } \\
\text { of Lyon (France) }\end{array}$ \\
\hline \multirow{10}{*}{ Araucaria } & \multirow{2}{*}{ Araucaria } & $\begin{array}{l}\text { angustifolia } \text { (Bertol.) Kuntze } 1898 \\
\text { Syn. : A. braziliana, Columbea angustifolia } \\
\text { Com. : Parana pine, candelabra tree }\end{array}$ & $\begin{array}{l}\text { South America } \\
\text { (Brazil, North Argentina } \\
\text { \& Paraguay) }\end{array}$ & $\begin{array}{l}\text { Botanical Garden } \\
\text { of Lyon (France) }\end{array}$ \\
\hline & & $\begin{array}{l}\text { araucana (Molina) K. Koch (1873) } \\
\text { Syn. : A. imbricata } \\
\text { Com. : monkey puzzle tree }\end{array}$ & $\begin{array}{l}\text { South America } \\
\text { (S. Chile \& } \\
\text { SW. Argentina) }\end{array}$ & $\begin{array}{l}\text { Botanical Garden of Montet } \\
\text { (Nancy, France) }\end{array}$ \\
\hline & Bunya & $\begin{array}{l}\text { bidwillii Hooker ( } 1843) \\
\text { Com. : bunya, bunya pine }\end{array}$ & $\begin{array}{l}\text { Australia } \\
\text { (Queensland) }\end{array}$ & $\begin{array}{l}\text { Botanical Garden of the } \\
\text { Villa Thuret (France) }\end{array}$ \\
\hline & \multirow{5}{*}{ Eutecta } & $\begin{array}{l}\text { bernieri Buchholz } 1949 \\
\text { Com. : Bernier's araucaria }\end{array}$ & New Caledonia & $\begin{array}{l}\text { Botanical Garden } \\
\text { of Lyon (France) }\end{array}$ \\
\hline & & $\begin{array}{l}\text { cunninghamii Aiton ex Lambert (1837) } \\
\text { Com. : Hoop pine, Moreton Bay pine }\end{array}$ & $\begin{array}{l}\text { Australia (Queensland \& } \\
\text { North of New South Wales) }\end{array}$ & $\begin{array}{l}\text { Botanical Garden of Montet } \\
\text { (Nancy, France) }\end{array}$ \\
\hline & & $\begin{array}{l}\text { heterophylla (Salisb.) Franco (1952) } \\
\text { Syn. : A. excelsa, Dombeya excelsa, Eutassa heterophylla } \\
\text { Com. : Norfolk Island pine }\end{array}$ & Norfolk Island & Found in the trade \\
\hline & & $\begin{array}{l}\text { laubenfelsii Corbasson (1968) } \\
\text { Com. : De Laubenfels araucaria }\end{array}$ & South of New Caledonia & $\begin{array}{l}\text { Botanical Garden } \\
\text { of Lyon (France) }\end{array}$ \\
\hline & & $\begin{array}{l}\text { nemorosa de Laubenfels (1969) } \\
\text { Com. : Boise araucaria }\end{array}$ & South of New Caledonia & $\begin{array}{l}\text { Botanical Garden of } \\
\text { Lyon (France) }\end{array}$ \\
\hline & Intermedia & / & New Guinea & \\
\hline & Wollemia & $\begin{array}{l}\text { nobilis Johns, Hill and Allen (1994) } \\
\text { Com. : Wollemi pine }\end{array}$ & $\begin{array}{l}\text { Australia } \\
\text { (Wollemi National Park) }\end{array}$ & Wollemi Pine France \\
\hline
\end{tabular}

most Agathis species occupy the tropical islands (Dettmann and Clifford, 2005). These two genera, extending within the equatorial region of New Guinea and Southeast Asia at lower latitude grow under a mesothermal climate, limited to the lower montane zone (Kershaw and Wagstaff, 2001). The monotypic genus Wollemia is by far the most endemic genus and its few wild species (about 40 adult plants) live deep in a wilderness rainforest of the Wollemi National Park in New South Wales (Australia).

\subsubsection{Fossil Araucariaceae}

Appearance and evolution of Araucariaceae are recorded by both macrofossils and pollen in sedimentary series all around the world. The first pollen record is from the early Triassic of Australia (as ancestor) just after the Permo-Triassic extinction, and the unequivocal Araucariaceae representatives were found in the Middle Jurassic of North Yorkshire (Stockey, 1982; Kershaw and Wagstaff, 2001; Kunzmann, 2007b). The maximum worldwide distribution was achieved in both hemispheres during the Cretaceous (Krassilov, 1978; Kunz- mann, 2007b). Their distribution was then reduced during the Middle Palaeocene to the Southern Hemisphere, with an extension to the Northern Hemisphere (restricted to South-East Asia).

During the Jurassic, Araucaria (especially the Eutacta and the Bunya sections) was the first genus to appear and diversify. Its macrofossils and pollens broadened a wide range of habitats in the two hemispheres (Gondwana and Laurasia), where Jurassic climate condition was subtropical to warmtemperate (Kershaw and Wagstaff, 2001). During the Cretaceous, the first effective Agathis and Wollemia fossils appeared, but remained restricted to Australia and New Zealand (Hill and Bigwood, 1987; Stockey, 1994). This palaeogeographic limitation could have been due to the break-up of palaeofloristic exchanges between Gondwana and Laurasia. Moreover, appearance of angiosperms during the Cretaceous also forced Agathis to be more competitive (Kershaw and Wagstaff, 2001), Wollemia probably evolved under similar circumstances. At the end of the Cretaceous, Araucaria genus began to leave the Northern Hemisphere. As pointed 
out by Kunzmann (2007b), their retreat from Northern Hemisphere coincides with two major events in Earth history: (1) major changes in forest composition in Europe and North America, and (2) rapid environmental changes across the KPg boundary.

Later, during the Cenozoic, Wollemia and especially Agathis became more prominent from the early Eocene to the early Oligocene. This development was synchronous with the diversification of angiosperms. Owing to their adaptation ability to many unfavourable conditions, such as the ultramafic soils on peridotites and the unstable climate in islands, Agathis species began to colonize and diversify in New Caledonia and other Asia-Pacific islands (Jaffré, 1995). In parallel there was a reduction of Agathis from south-eastern Australia due to the cooler conditions at high latitudes. Regarding Araucaria species, they regenerated from early Miocene under subtropical to warm-temperate conditions (Kershaw and Wagstaff, 2001).

\subsubsection{Usefulness of Araucariaceae from the past to present days}

The worldwide patchy and sparse distribution of Araucariaceae in sedimentary deposits, as inferred by palaeobotanic and palynological data, can thus provide valuable palaeoclimatic information. Indeed, they preferentially grow under warm and wet conditions, mainly in equatorial, tropical or subtropical rainforests as well as peat swamps (Kershaw and Wagstaff, 2001).

Furthermore, many Araucariaceae produce resins having archaeological and economical values. Agathis is highly considered as a source of attractive, straight-grained, easily worked timber. The wood of Agathis australis has been intensively used in the past for the construction of canoes, houses and cult objects by native Maori people of New Zealand. Some of these objects were well preserved and are of archaeological interest nowadays. The resin of Agathis (kauri copal, kauri gum or kauri resin) was also widely used for the manufacture of paints, varnishes and linoleum during the XIX and XX centuries. Other Agathis living in Indonesia and Philippines, as Agathis dammara, produce resin having an important economic value (Manilla resin or Manilla copal). Copal has also been used for a long time in jewellery and related arts. Furthermore, Araucaria may not have an equivalent economical value as Agathis, but provided wood for ship building during several centuries.

\subsection{Chemotaxonomy}

Available data on the composition of monoterpenoids $\left(\mathrm{C}_{10}\right)$, sesquiterpenoids $\left(\mathrm{C}_{15}\right)$ and diterpenoids $\left(\mathrm{C}_{20}\right)$ of many Araucariaceae representatives are here summarized.

Monoterpenoids $\left(\mathrm{C}_{10}\right)$ are abundantly synthesized by Araucariaceae. Compounds, like pinene, thujene and limonene are widespread in most Araucariaceae species
(Brophy et al., 2000). They represent the major components of araucarian essential oils (Brophy et al., 2000; Staniek et al., 2010). Furthermore, owing to their lower molecular weight, these chemicals are generally highly volatile and not readily preserved in sediments.

Sesquiterpenoids are composed by monocyclic (e.g. elemane, germacrane and humulane types), bicyclic (e.g. cadinane, copaane, muurolane and caryophyllane types) and tricyclic (e.g. aromadendrane, cubebane and gurjunane types) compounds. These chemicals are mainly represented by unsaturated hydrocarbons, alcohols and acids, constituents of essential oil and resins (e.g. Pietsch and König, 2000; Brophy et al., 2000). However, they are common in conifers as well as in other plants like angiosperms and bryophytes (Otto and Wilde, 2001).

Regarding diterpenoids, they are represented by bicyclic, tricyclic and tetracyclic compounds. Bicyclic diterpenoids mainly composed by labdane-type compounds are common in all conifers. They are synthesized as unsaturated hydrocarbons (like sclarenes and biformenes), and alcohols (like sclareols) as well as acids (like agathic and communic acids) and isomers may occur (Caputo and Mangoni, 1974; Caputo et al., 1974a, b, 1976; Thomas, 1969, Pietsch and König, 2000; Otto and Wilde, 2001). Other bicyclic compounds belonging to the clerodane type, like clerodadienic acids, seem to be restricted to two Araucaria species: A. bidwillii (Caputo and Mangoni, 1974) and A. hunsteinii (Otto and Wilde, 2001).

Tricyclic diterpenoids reported in Araucariaceae are composed essentially of the abietane and pimarane types. Tetracyclic diterpenoids belong to the beyerane, kaurane, phyllocladane, trachylobane and atisane types (Brophy et al., 2000; Otto and Wilde, 2001). According to Thomas (1969), Brophy et al. (2000) and Pietsch and König (2000), both tri- and tetracyclic diterpenoids are synthesized as unsaturated hydrocarbons (like pimaradienes, abietadienes, kaurenes, etc.), acids (like abietic and isopimaric acids) and more rarely as alcohols (like phyllocladanol and phenolic abietanes, which are only reported in few Agathis species) in Araucaraiceae species.

Distribution of bioterpenoids varies from one species to another in fresh plants (Thomas, 1969; Brophy et al., 2000). For instance, each species seems to be dominated by one or possibly two compounds. Their molecular composition could thus be theoretically specific to each araucarian species and/or genus. These data originate from a compilation of several studies, and some inconsistencies may occur. For instance, Thomas (1969) insists on the presence of compounds like agathic, communic, isopimaric and abietic acids in Agathis species, while these compounds are not reported by Brophy et al. (2000). Such kinds of contradictions are certainly due to the fact that the former studied the resins while the last studied essential oil. Nevertheless, chemotaxonomic data provide valuable knowledge to palaeochemotaxonomy. 


\section{Samples and experimental procedures}

\subsection{Samples}

Leaves and twigs of about 12 Araucariaceae species were selected for this study, including 3 Agathis, 8 Araucaria and 1 Wollemia. Choice of leaves and twigs as plant material in this study is done based on the following reasons. (1) Most of sedimentary organic matter originating from conifers comes from leaves and twigs. (2) Plant biomarkers investigated in this paper derive from terpenoids that are of the major components of essential oils and resins. The terpenoids are transported with resins through vessels to all part of a plant, including leaves and twigs. (3) Analysis of the molecular composition of leaves and twigs provided currently available relevant chemotaxonomic and even some palaeochemotaxonomic data. More details of representatives, their phylogenetic relationships, native geographic distributions as well as their provenances are given in the Table 1. This sampling is believed to be well representative of the intrinsic variability of the Araucariaceae family.

\subsection{Experimental and analytical procedures}

This study focuses on the diagenetic molecular signature of Araucariaceae. Transformation of fresh material to its diagenetic counterpart was carried out by experimental artificial maturation by confined pyrolysis, developed by Hautevelle et al. (2006b). Twigs and leaves of the selected plants were finely cut and dried under vacuum for $24 \mathrm{~h}$ in a desiccator at $45^{\circ} \mathrm{C}$ before being crushed. The plants to be pyrolysed were introduced into gold tubes with and without $\mathrm{LiAlH}_{4}$ (Fluka No. 62420, purity $97 \%$, powder form). The use of $\mathrm{LiAlH}_{4}$ favours the generation of saturated over aromatic terpanes during pyrolysis. The filled gold tubes were then sealed under an argon atmosphere and introduced into autoclaves and heated at $280^{\circ} \mathrm{C}$ and 700 bars during $24 \mathrm{~h}$. These parameters of pyrolysis were determined to obtain the broadest distribution of biomarkers (aliphatic, aromatic and polar). Biomolecules of the starting fresh plant samples of each representative were also studied.

The soluble organic compounds of fresh plants and their pyrolysates were extracted under $80^{\circ} \mathrm{C}$ and 100 bars using $\mathrm{CH}_{2} \mathrm{Cl}_{2}$ with an accelerated solvent extractor (ASE 350, Dionex). The total extract was then fractionated into aliphatic, aromatic and polar fractions using liquid chromatography on alumina (separation of hydrocarbon and polar fraction) and silica (separation of aliphatic and aromatic fractions from the hydrocarbon fraction) columns. The fractions were successively eluted with $\mathrm{CH}_{2} \mathrm{Cl}_{2}$ and $\mathrm{CH}_{3} \mathrm{OH} / \mathrm{CH}_{2} \mathrm{Cl}_{2}$ $(50 / 50 \mathrm{v} / \mathrm{v})$ on the alumina column, then with pentane, followed by pentane/CH2Cl2 $(65 / 35 v / v)$ and $\mathrm{CH}_{3} \mathrm{OH} / \mathrm{CH}_{2} \mathrm{Cl}_{2}$ $(50 / 50 v / v)$ on the silica column. The obtained fractions were diluted in hexane $\left(4 \mathrm{mg} \mathrm{mL}^{-1}\right.$ for aliphatic fraction and $8 \mathrm{mg} \mathrm{mL}^{-1}$ for the others) before analysis by GC-MS.

\subsection{Gas Chromatography-Mass Spectrometry (GC-MS) and identification of compounds}

Aliphatic and aromatic fractions were analysed using an HP 5890 Series II gas chromatograph coupled with an HP 5971 mass spectrometer (GC-MS). Polar fractions were silylated using N, O-bis-(trimethylsilyl)trifluoroacetamide (BSTFA) at $60^{\circ} \mathrm{C}$ for $15 \mathrm{~min}$ before analysis. The capillary column was a DB-5 $\mathrm{J} \& \mathrm{~W}(60 \mathrm{~m} \times 0.25 \mathrm{~mm}$ i.d., with $0.1 \mu \mathrm{m}$ film thickness). The temperature programme was $70-315^{\circ} \mathrm{C}$ at $15^{\circ} \mathrm{C} \mathrm{min}^{-1}$ to $130^{\circ} \mathrm{C}$, and then $3^{\circ} \mathrm{C} \mathrm{min}^{-1}$ followed by an isothermal stage at $315^{\circ} \mathrm{C}$ for $15 \mathrm{~min}$. Helium was the carrier gas $\left(1 \mathrm{~mL} \mathrm{~min}^{-1}\right.$ flow rate). The MS operated in the electron impact mode (EI) at $70 \mathrm{eV}$ ionization energy, and mass spectra were scanned from 50 to $500 \mathrm{Da}$ using a quadrupole detector. Data were acquired and processed using the Agilent ChemStation software. Compounds were identified by comparison of mass spectra with the literature and library database (Wiley275) or by interpretation of mass spectrometric fragmentation patterns. Relative abundance of compounds was measured by integration of peak area.

\section{Results and discussion}

Aliphatic, aromatic and polar fractions were studied for each Araucariaceae representative, including the extracts of fresh plants and of their pyrolysates. Since our study mainly focuses on palaeochemotaxonomy, the extracts of pyrolyzed plants were preferentially studied.

\subsection{Molecular characteristics of artificially diagenetic Araucaria genus}

\subsubsection{Sesquiterpenoids}

Distribution of aliphatic and aromatic sesquiterpenoids of Araucaria is respectively shown in Figs. 2 and 3. The proportion of detected sesquiterpenoids in each representative is given in Tables 2 and 3, which respectively correspond to compositions of saturated and aromatic compounds obtained from pyrolysis with and without $\mathrm{LiAlH}_{4}$. Di- and trimethylnaphthalenes are ubiquitous in each representative. Araucaria species are also commonly characterized by the following:

- farnesane $\left(\mathrm{C}_{15} \mathrm{H}_{32}\right)$ and bisabolane-type compounds. Acyclic farnesane, probably derived from isomers of farnesol (trans- and cis-) detected in the fresh plants, is identified in all Araucaria species. Bisabolanetype compounds, like isomers of saturated bisabolane $\left(\mathrm{C}_{15} \mathrm{H}_{30}\right)$, ar-curcumene $\left(\mathrm{C}_{15} \mathrm{H}_{22}\right)$ and dihydro-arcurcumene $\left(\mathrm{C}_{15} \mathrm{H}_{24}\right)$, are observed in the aliphatic and the aromatic fraction respectively. Ar-curcumene is often found in trace amounts for all species. Bisabolane-type compounds are generally derived from 


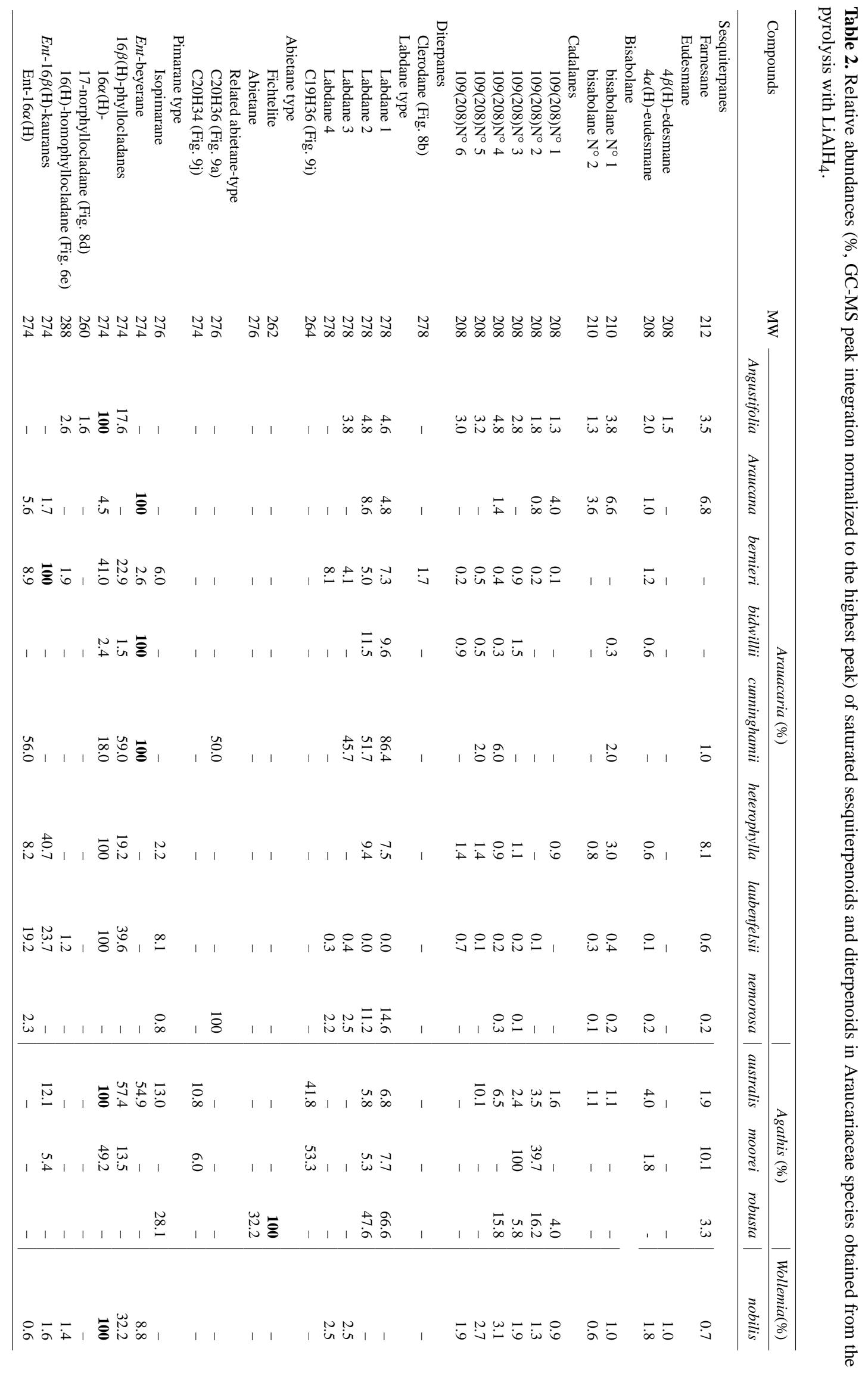




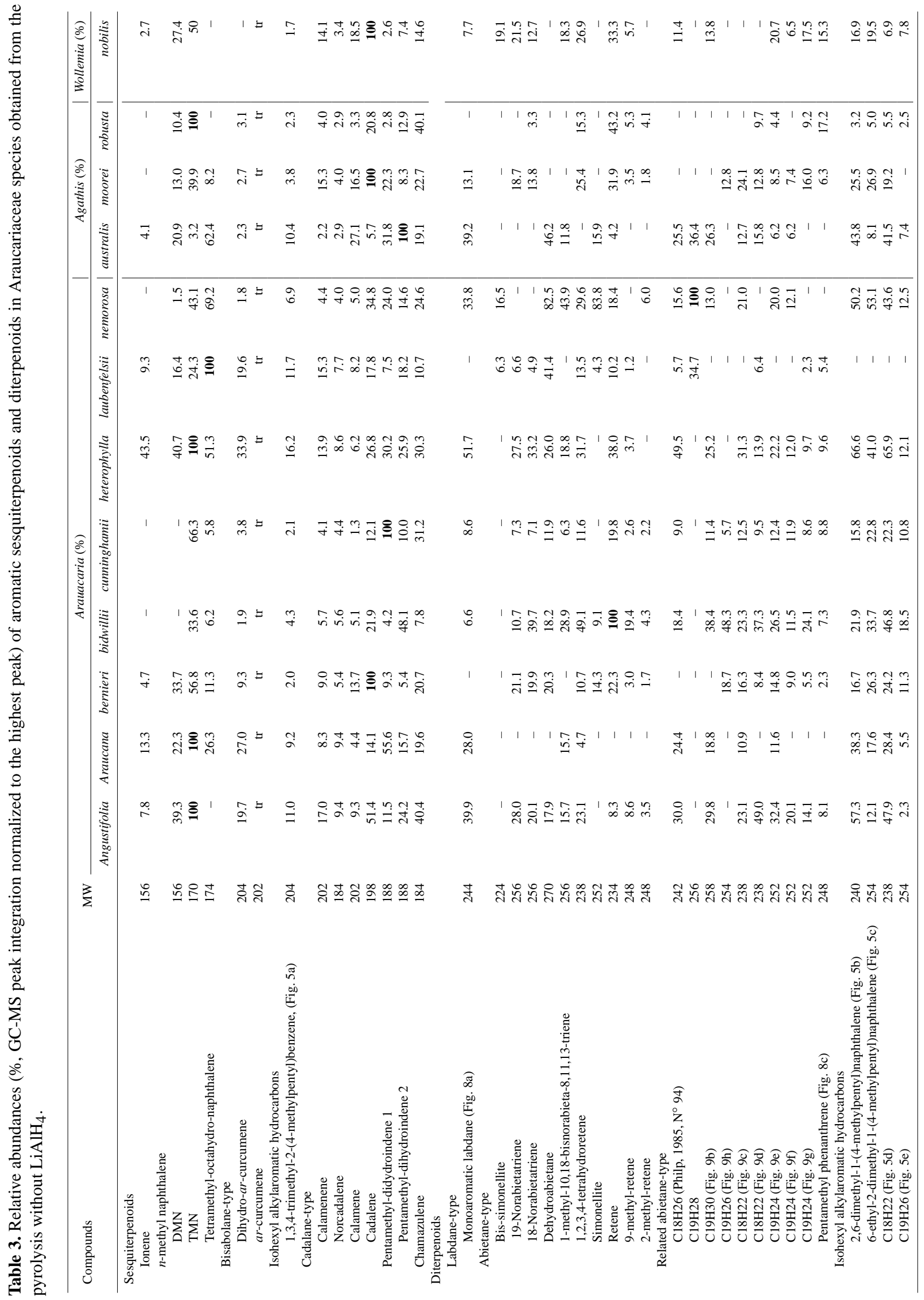




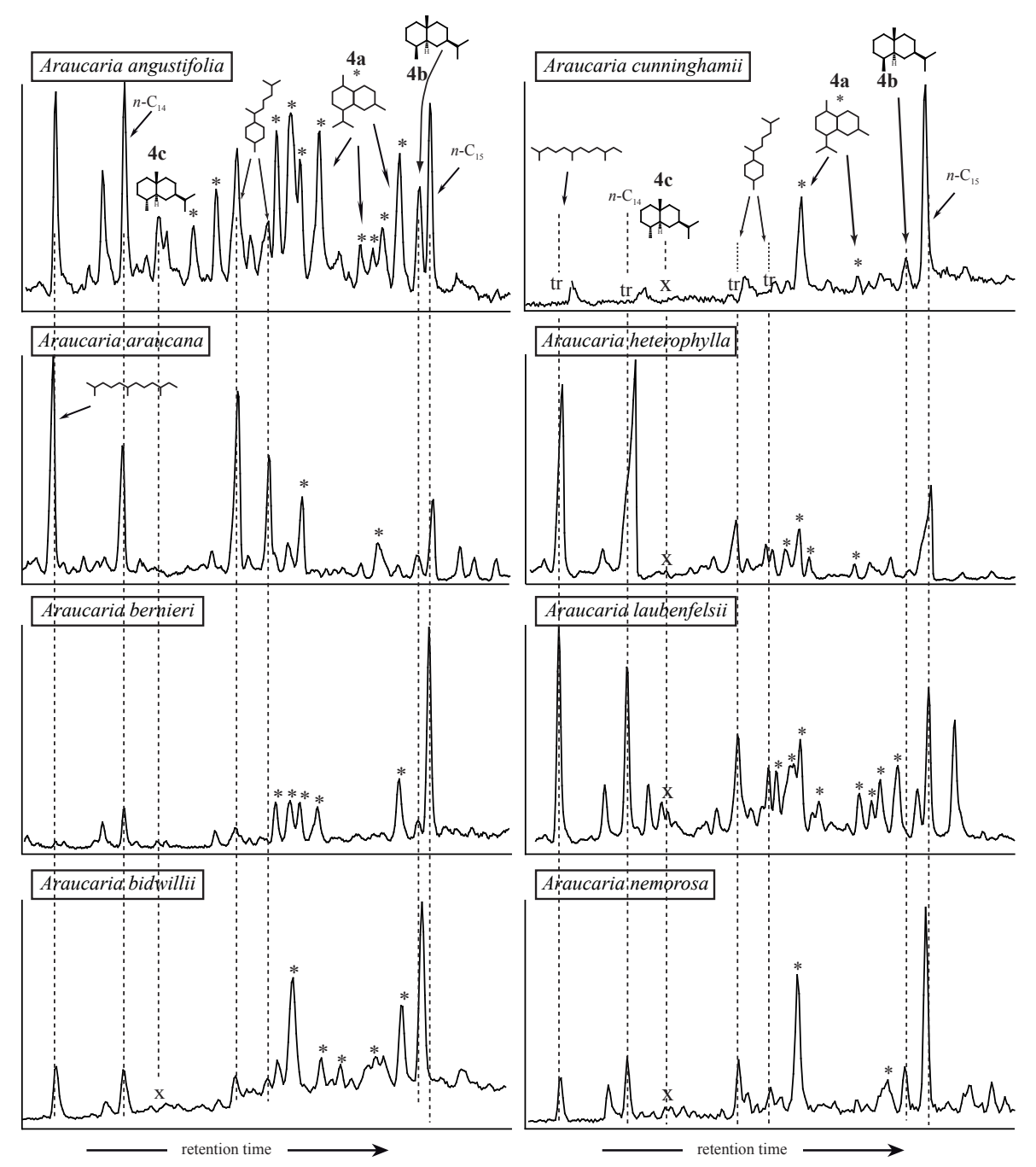

Fig. 2. Partial chromatograms (sesquiterpenoids retention time window) of aliphatic fraction of pyrolysates of Araucaria species. The mass spectra of 4a, 4b, and 4c are given in Fig. 4. $x$ : absence of compound; tr: at trace level; *: cadalane-type compounds.

bisabolenes found in the fresh plants. They represent one of the major class of Araucaria sesquiterpenoids (especially in the aliphatic fractions), except for $A$. bernieri and A. bidwillii;

- cadalane-type compounds. They are mainly derived from cadinol and cadinenes, which are ubiquitous in vascular plants. In the aliphatic fractions, a variety of saturated cadalane-type compounds $\left(\mathrm{C}_{15} \mathrm{H}_{28}\right)$ are identified like cadinanes, muurolanes and amorphanes. Their spectra are commonly characterized by a molecular ion at $m / z$ 208, a low abundance (even absent) of the $\mathrm{M}^{+}-15$ ion at $m / z 193$, a relatively high abundance of ion at $m / z 165$ (corresponding to the loss of a isopropyl unit, $\mathbf{M}^{+}-43$ ) and a base peak at $m / z, 109$ (corresponding to a fragmentation of A/B-ring moiety after the loss of precedent units) (Fig. 4a). In the aromatic fractions, the cadalane-type compounds are repre- sented by calamenene and calamene $\left(\mathrm{C}_{15} \mathrm{H}_{22}\right.$, both partially aromatized), cadalene $\left(\mathrm{C}_{15} \mathrm{H}_{18}\right.$, completely aromatized). One norcadalene (probably the 1-isopropyl7-methylnaphthalene according to the spectrum from Singh et al., 1994) is detected in all species (Fig. 4d). Its formation is the result of the demethylation of cadalanetype compounds, and no more precision to its structure was proposed. In addition, cadalane-type compounds show a high abundance in most species' samples and represent also one of the major Araucaria sesquiterpenoids, except for A. araucana and A.cunninghamii;

- eudesmane-type compounds. $4 \alpha(\mathrm{H})$-eudesmane and $4 \beta(\mathrm{H})$-eudesmane are identified according to Wiley275 database and the spectrum published by Alexander et al. (1983) (Fig. 4b and 4c). The relative abundances of these two compounds vary from one species to another. It is higher in A. bernieri and at trace level in A. het- 


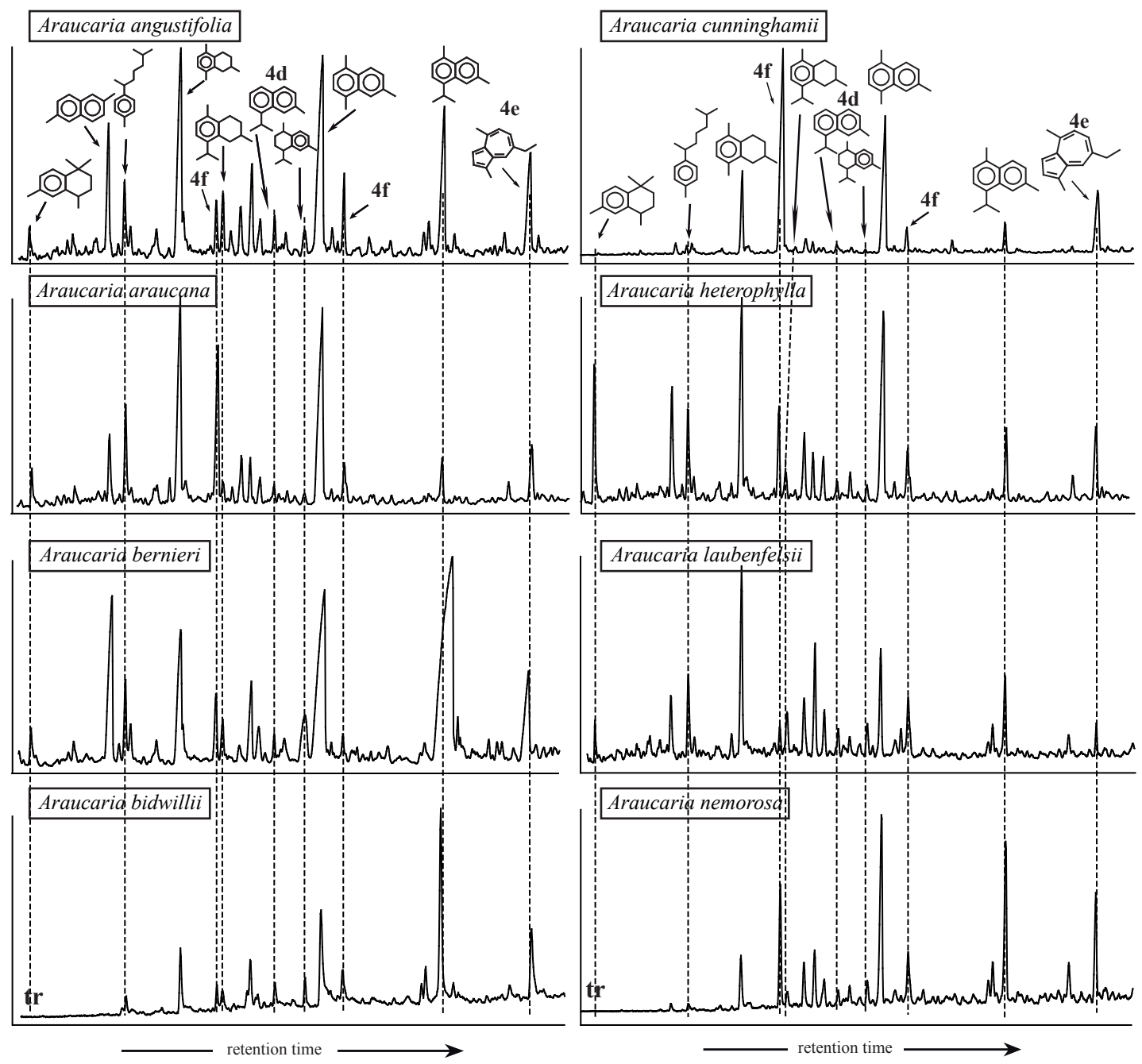

Fig. 3. Partial chromatograms (sesquiterpenoids retention time window) of aromatic fraction of pyrolysates of Araucaria species. The mass spectra of 4d, 4e and $4 \mathrm{f}$ are given in Fig. 4. tr: at trace level.

erophylla as well as in A. cunninghamii. Moreover, eudesmanes-type compounds are widely distributed in fossil vascular plants (Alexander et al., 1983). However, they were not reported in the previous studies of Brophy et al. (2000) and Otto and Wilde (2001), which focus on fresh material;

- ionene $\left(\mathrm{C}_{13} \mathrm{H}_{18}\right)$, with a molecular ion at $\mathrm{m} / \mathrm{z} 174$ and a base peak at $\mathrm{m} / \mathrm{z} 159$ according to Achari et al. (1973). It was detected for most of Araucaria species. It could be derived from $\beta$-carotene (like in sporopollenin (which derives from some pollen exines) (Achari et al., 1973; Simoneit, 1986). In our case, the ionene is probably directly derived from ionone that is abundant in fresh plants;
- chamazulene $\left(\mathrm{C}_{14} \mathrm{H}_{16}\right)$ and other compounds identified as pentamethyl-2,3-dihydroindenes according to their spectra are also remarkable in the aromatic fraction. Chamazulene elutes after cadalene and its spectrum, according to the Wiley275 database, is quite similar to that of norcadalene, but with a molecular ion $(\mathrm{m} / \mathrm{z}$ 184) more intense than its base peak at $m / z 169$ (Fig. 4e). Due to its carbon skeleton composed of a ring composed of seven carbon atoms and a pentenic ring, it is probably derived from precursor of similar carbon skeleton, like aromadendrenes, alloaromadendrene and spathulenol, which are widespread in the fresh species (Brophy et al., 2000; Olawore, 2005). Pentamethyl2,3-dihydroindene, identified according to Wiley275 database, is characterized by a spectrum with a molecular ion at $m / z 188\left(\mathrm{C}_{14} \mathrm{H}_{20}\right)$ and a base peak at $m / z 173$ $\left(\mathrm{M}^{+}-15\right)$ (Fig. 4f). Pentamethyl-2,3-dihydroindene and chamazulene show a higher abundance than other 

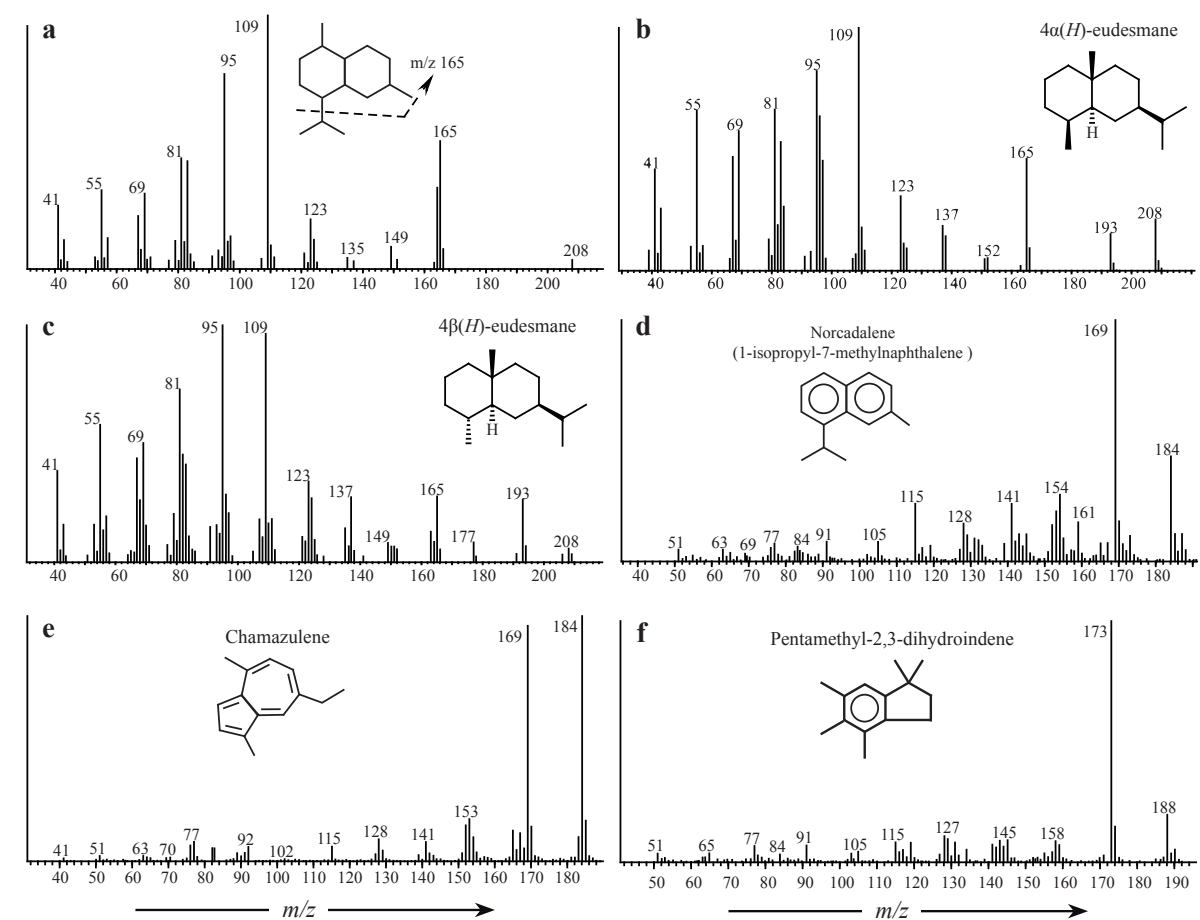

Fig. 4. Mass spectra of some identified Araucariaceae sesquiterpenoids. (a): saturated cadalane-type compounds; (b): $4 \alpha(\mathrm{H})$-eudesmane (identified using Wiley275 database); (c): $4 \beta(\mathrm{H})$-eudesmane (identified from spectrum in Alexander et al., 1983); (d): norcadalene (identified from spectrum in Singh et al., 1994); (e): chamazulene (identified using Wiley275 database); (f): pentamethyl-2,3-dihydroindene (identified using Wiley275 database).

aromatic bicyclic sesquiterpenoids with the exception of cadalene;

- furthermore, 1,3,4-trimethyl-2-(4-methylpentyl)benzene $\left(\mathrm{C}_{15} \mathrm{H}_{24}\right)$ with a molecular ion at $m / z 204$ and a base peak at $m / z 133$ was detected in all Araucaria species, but with a low abundance. According to Ellis et al. (1996), it belongs to the family of isohexyl alkylaromatic hydrocarbons with an opened A-ring (Fig. 5a). Its occurrence could be due to the alteration of some bicyclic compounds (like drimane) during the pyrolysis.

In addition, the general trend of Araucaria sesquiterpenoids, represented by the relative abundance of major class of sesquiterpenoids in each representative, is given in Table 4 .

\subsubsection{Diterpenoids}

Diterpenoids in the extracts of pyrolysates of Araucaria species are characterized by a diversity of bicyclic, tricyclic and tetracyclic compounds. Distributions of saturated and aromatic diterpenoids are respectively shown in Figs. 6 and 7; the relative proportion of each diterpenoid is given in Tables 2 and 3.

\section{Bicyclic diterpenoids}

Bicyclic diterpenoids are essentially composed by labdanetype compounds $\left(\mathrm{C}_{20} \mathrm{H}_{38}\right)$. Several isomers of labdane are identified in Araucaria species, although they do not show a high abundance in each representative. As shown in the literature, they are generally derived from labdadiene, phenolic labdanes and communic acids present in the fresh Araucara (Caputo and Mangoni, 1974; Caputo et al., 1974a, b, 1976; Otto and Wilde, 2001). Moreover, according to de Paiva Campello and Fonseca, (1975), agathic acid could also be the origin of labdanes in the case of A. angustifolia.

A peak having a molecular ion at $m / z 244\left(\mathrm{C}_{18} \mathrm{H}_{28}\right)$ is detected in the aromatic fraction in all Araucaria species. It shows significant abundance in most species, but in traces for A. bidwillii, A. laubenfelsii and A. nemorosa. According to its mass spectrum, its base peak at $m / z 159$ matches very well to fragments composed of two rings (including an aromatic ring) and two methylene units. This fragment is probably formed via the loss of a branched chain with 6 carbon atoms (Fig. 8a). This kind of fragmentation seems to be consistent with a monoaromatic labdane. No aromatic labdane has been described in the literature until now.

Another peak having a molecular ion at $m / z 278\left(\mathrm{C}_{20} \mathrm{H}_{38}\right)$ and a base peak at $m / z, 109$ is detected with a low abundance in the aliphatic fraction of $A$. bidwillii. Its mass spectrum 


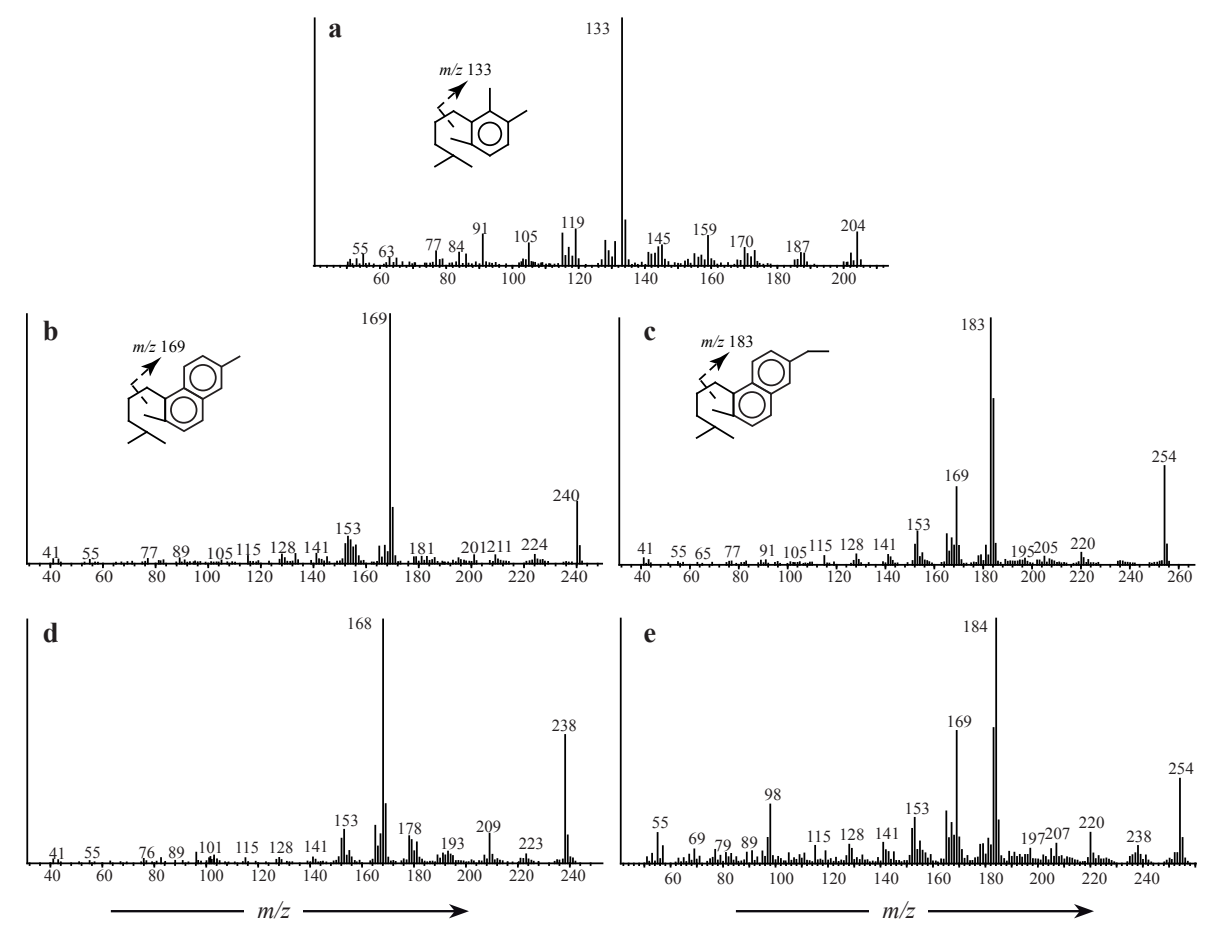

Fig. 5. Mass spectra of identified isohexyl alkylaromatic hydrocarbons in Araucariaceae species and mass spectral cleavage patterns (identified after Ellis et al., 1996). (a): 1,3,4-trimethyl-2-(4-methylpentyl)benzene; (b): 2,6-dimethyl-1-(4-methylpentyl)- naphthalene; (c): 6-ethyl2-dimethyl-1-(4-methylpentyl)-naphthalenemethylretene. Mass spectra of some unidentified Araucariaceae diterpenoids, but similar to some of the identified isohexyl alkylaromatic hydrocarbons: (d) to (b) and (e) to (c).

Table 4. Major sesquiterpenoids and diterpenoids classes detected in Araucariaceae species after confined pyrolysis with (saturated compounds) and without (aromatic compounds) $\mathrm{LiAlH}_{4}$ as reducing agent.

\begin{tabular}{|c|c|c|c|c|c|c|c|c|c|c|c|c|c|}
\hline & \multirow{2}{*}{ Class of structure } & \multicolumn{3}{|c|}{ Agathis } & \multicolumn{8}{|c|}{ Araucaria } & \multirow{2}{*}{$\frac{\text { Wollemia }}{\text { nobilis }}$} \\
\hline & & australis & moorei & robusta & angustifolia & araucana & bidwillii & bernieri & cunninghamia & heterophylla & laubenfelsii & nemorosa & \\
\hline 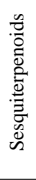 & $\begin{array}{l}\text { Farnesane } \\
\text { Bisabolane } \\
\text { Eudesmane } \\
\text { Cadalane } \\
\text { Ionene } \\
\text { Chamazulene } \\
\text { Pentamethyl-dihydroindene }\end{array}$ & $\begin{array}{c}+++ \\
+ \\
+++ \\
++++ \\
+ \\
++ \\
+ \\
+\end{array}$ & $\begin{array}{c}++ \\
\text { tr } \\
\operatorname{tr} \\
++++ \\
\text { tr } \\
++ \\
+ \\
+\end{array}$ & $\begin{array}{c}+ \\
\operatorname{tr} \\
\operatorname{tr} \\
++ \\
\operatorname{tr} \\
++ \\
+ \\
+\end{array}$ & $\begin{array}{c}+++ \\
+++ \\
++ \\
++++ \\
+ \\
+++ \\
++ \\
+\end{array}$ & $\begin{array}{c}+++ \\
++++ \\
+ \\
++ \\
+ \\
++ \\
+ \\
+\end{array}$ & $\begin{array}{c}+ \\
+ \\
++ \\
++++ \\
\text { tr } \\
++ \\
+ \\
+\end{array}$ & $\begin{array}{c}++ \\
+ \\
+ \\
++++ \\
+ \\
+++ \\
+ \\
\end{array}$ & $\begin{array}{c}+ \\
\operatorname{tr} \\
\operatorname{tr} \\
++ \\
\operatorname{tr} \\
++ \\
\operatorname{tr}\end{array}$ & $\begin{array}{c}+++ \\
++ \\
\operatorname{tr} \\
+++ \\
++ \\
++ \\
++\end{array}$ & $\begin{array}{c}+++ \\
++ \\
+ \\
+++ \\
\operatorname{tr} \\
++ \\
++ \\
+\end{array}$ & $\begin{array}{c}++ \\
+ \\
+ \\
+++ \\
\operatorname{tr} \\
+++ \\
++\end{array}$ & $\begin{array}{c}++ \\
+ \\
++ \\
++++ \\
\text { tr } \\
1 \\
+ \\
\end{array}$ \\
\hline \multirow{3}{*}{ 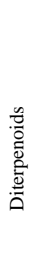 } & $\begin{array}{l}\text { Labdane } \\
\text { Isohexyl alkylaromatic hydrocarbons } \\
\text { Abietane }\end{array}$ & $\begin{array}{c}+ \\
++\end{array}$ & $\begin{array}{c}+ \\
++\end{array}$ & $\begin{array}{c}++ \\
+\end{array}$ & $\begin{array}{c}++ \\
++++\end{array}$ & $\begin{array}{c}++ \\
++++\end{array}$ & $\begin{array}{c}+++ \\
++\end{array}$ & $\begin{array}{l}+++ \\
+++\end{array}$ & $\begin{array}{c}++ \\
+++\end{array}$ & $\begin{array}{c}++ \\
++++\end{array}$ & $\begin{array}{c}+ \\
++\end{array}$ & $\begin{array}{c}+++ \\
++\end{array}$ & $\begin{array}{c}+ \\
++\end{array}$ \\
\hline & $\begin{array}{l}\text { normal abietane (dehydroabietic acid) } \\
\text { phenolic abietane (ferruginol, sugiol } \\
\text { and hinokiol) }\end{array}$ & $\begin{array}{l}+ \\
\text { tr }\end{array}$ & $\begin{array}{l}+ \\
\operatorname{tr}\end{array}$ & $\begin{array}{l}+ \\
\operatorname{tr}\end{array}$ & $\begin{array}{l}+ \\
\text { tr }\end{array}$ & $\begin{array}{l}+ \\
\text { tr }\end{array}$ & $\begin{array}{l}+ \\
\text { tr }\end{array}$ & $\begin{array}{l}+ \\
\text { tr }\end{array}$ & $\begin{array}{l}+ \\
\text { tr }\end{array}$ & $\begin{array}{l}+ \\
\text { tr }\end{array}$ & $\begin{array}{l}+ \\
\text { tr }\end{array}$ & $\begin{array}{l}+ \\
\text { tr }\end{array}$ & $\begin{array}{l}+ \\
\text { tr }\end{array}$ \\
\hline & $\begin{array}{l}\quad \text { diagenetic abietanes } \\
\text { Pimarane } \\
\text { Ent-beyerane } \\
\text { Phyllocladane } \\
\text { Ent-kaurane }\end{array}$ & $\begin{array}{c}++ \\
+ \\
++ \\
+ \\
+ \\
+++\end{array}$ & $\begin{array}{c}+++ \\
1 \\
1 \\
+ \\
+++\end{array}$ & $\begin{array}{c}+++ \\
1 \\
1 \\
1 \\
1\end{array}$ & $\begin{array}{c}+++ \\
1 \\
1 \\
+++ \\
1 \\
++\end{array}$ & $\begin{array}{c}\text { tr } \\
/ \\
+++ \\
++ \\
++ \\
++\end{array}$ & $\begin{array}{c}++++ \\
/ \\
+++ \\
\text { tr } \\
1\end{array}$ & $\begin{array}{l}++++ \\
\quad+ \\
\quad+ \\
++++ \\
++++\end{array}$ & $\begin{array}{c}+++ \\
/ \\
++ \\
++++ \\
++\end{array}$ & $\begin{array}{c}+++ \\
+ \\
\quad \\
+ \\
+++ \\
++++\end{array}$ & $\begin{array}{c}+++ \\
++ \\
\quad \\
+ \\
+++ \\
++++\end{array}$ & $\begin{array}{c}+++ \\
+ \\
1 \\
1 \\
+\end{array}$ & $\begin{array}{c}++++ \\
\quad \\
\quad+ \\
\quad \\
++++\end{array}$ \\
\hline
\end{tabular}

indicates that it could also be a bicyclic compound and has a similar carbon skeleton to labdane. Indeed, its fragment at $\mathrm{m} / \mathrm{z} 193$ matches to a configuration including two rings (A and $\mathrm{B}$ ) and three methylene units, while its $\mathrm{A} / \mathrm{B}$ ring fragment $(m / z$ 109) contains only two methylene units. The "third" methylene unit could thus only be bound at the carbon-9 position (Fig. 8b). This obtained configuration is consistent with a structure similar to that of clerodane. However, its report in extant conifers is limited to a few deriva- tives of ent-clerodadienes (Otto and Wilde, 2001) and is restricted to two Araucaria species including A. bidwillii (Caputo and Mangoni, 1974; Cox et al., 2007).

2,6-dimethyl-1-(4-methylpentyl)naphthalene and 6-ethyl2-dimethyl-1-(4-methylpentyl)-naphthalene are abundant for most species and in traces in A. launbenfelsii. These two compounds are identified from spectra published by Ellis et al. (1996) and given in Fig. 5b and 5c. They belong to the family of isohexyl alkylaromatic hydrocarbons 


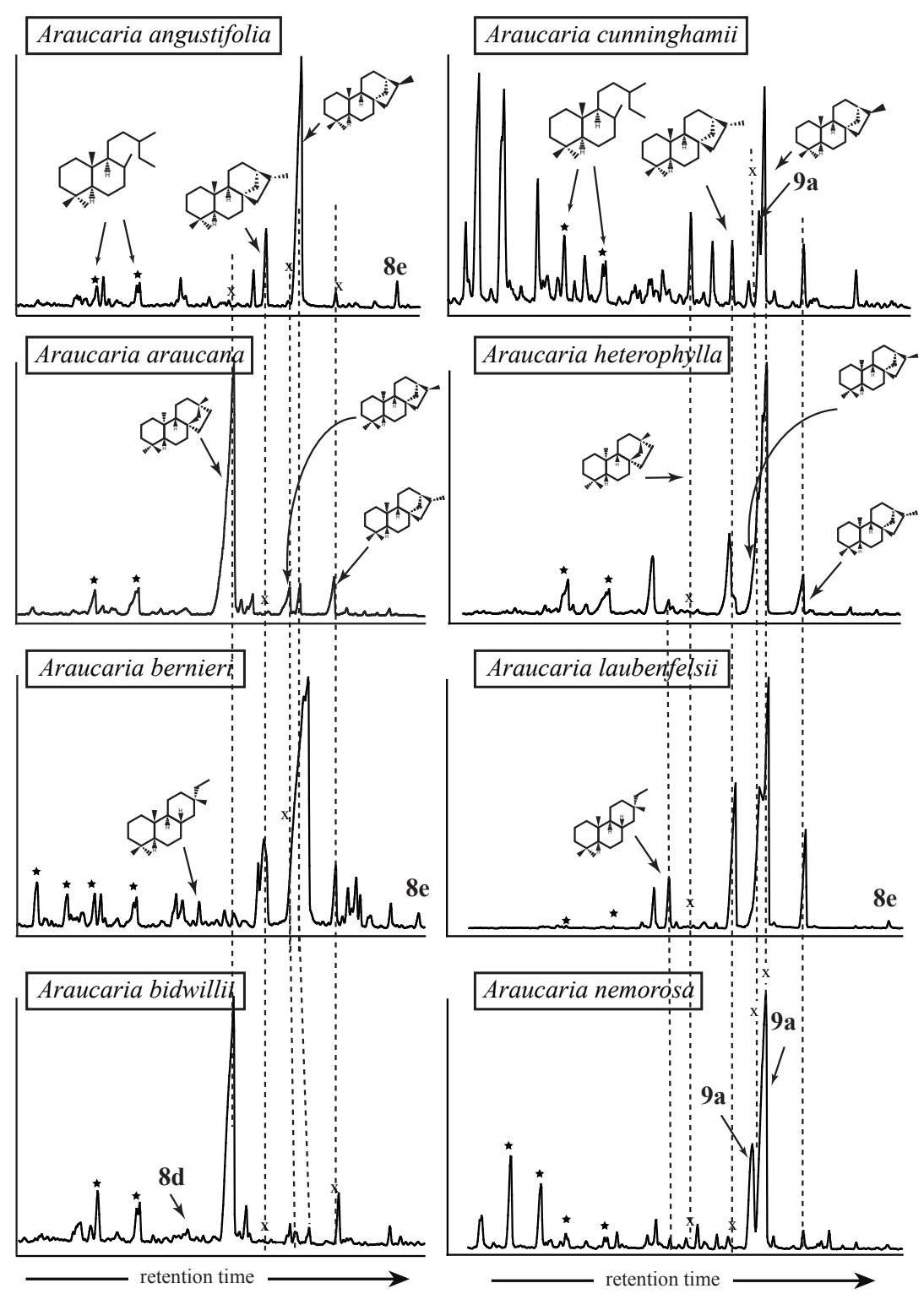

Fig. 6. Partial chromatograms (diterpenoids retention time window) of aliphatic fraction of pyrolysates of Araucaria species. The mass spectra of $8 \mathrm{~d}$ and $8 \mathrm{e}$ are given in Fig. 8. The mass spectrum of $9 \mathrm{a}$ is given in Fig. 9. $\star$ : labdanes; $x$ : absence of compound.

just like the 1,3,4-trimethyl-2-(4-methylpentyl)benzene previously described. Indeed, their specific carbon skeleton with an opened A-ring could be due to some specific chemical reactions, like aromatization, ring-opening processes and rearrangement during the maturation (Ellis et al., 1996). Furthermore, the co-occurrence of 2,6-dimethyl1-(4-methylpentyl)naphthalene and 6-ethyl-2-dimethyl-1-(4methylpentyl)-naphthalene suggests precursors like tricyclic diterpenoids (Ellis et al., 1996), for which the diagenetic products are structurally quite dissimilar to their precursors.

\section{Tricyclic diterpenoid}

Few aliphatic but a high diversity of aromatic tricyclic diterpenoids are observed. A pimarane-type compound, like isopimarane $\left(\mathrm{C}_{20} \mathrm{H}_{36}\right)$, is detected in the aliphatic fraction with a significant abundance for numerous species, like $A$. bernieri, A. heterophylla, A. laubenfelsii and A. nemorosa. This kind of tricyclic aliphatic diterpenoids is probably derived from isopimara-7, 15-dienes, 13-isopimaradiene, isopimara-8(9),15-diene as well as $8 \beta$-hydroxyisopimarene, that are detected in some of the fresh Araucara species. 


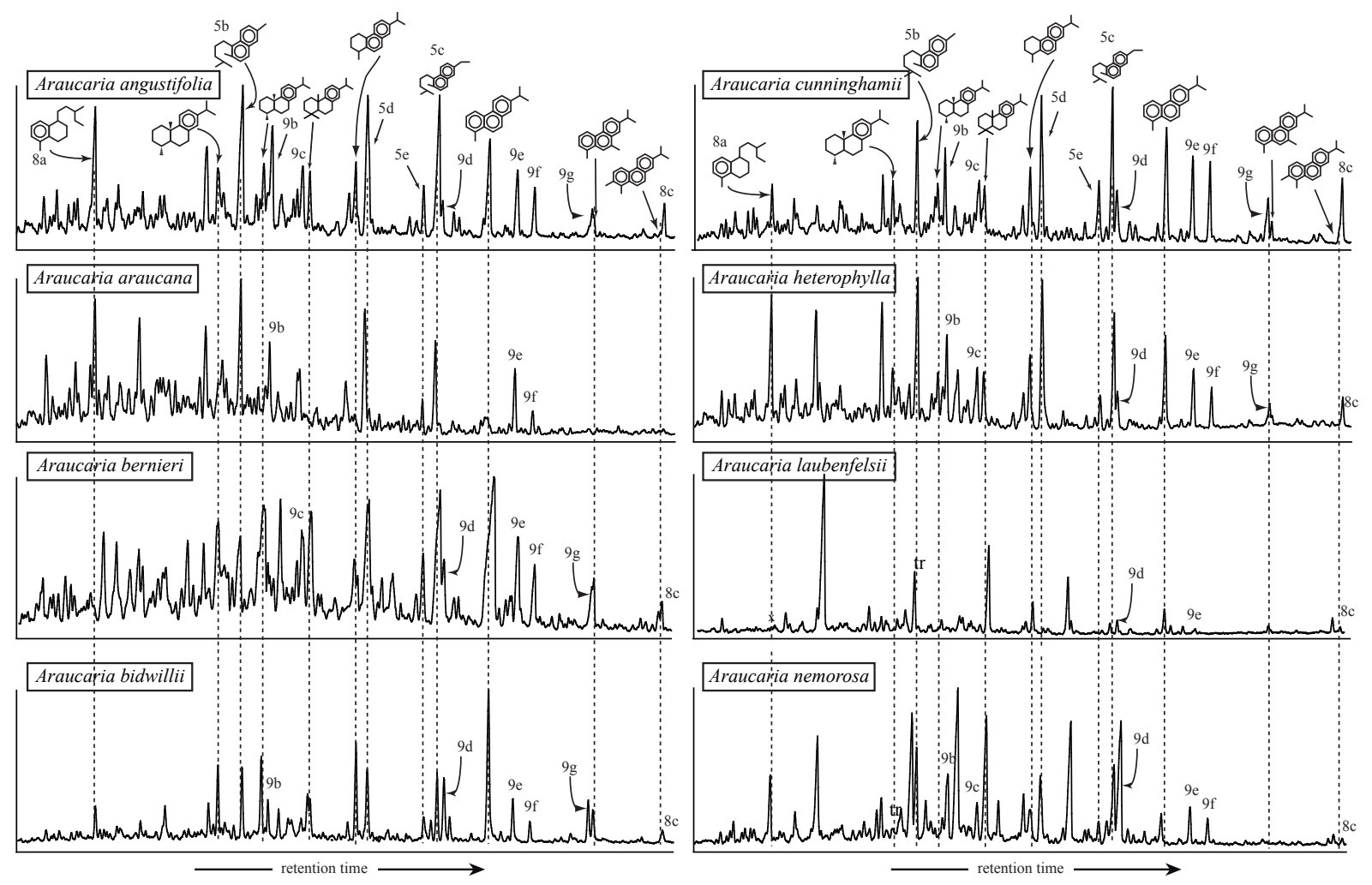

Fig. 7. Partial chromatograms (diterpenoids retention time window) of aromatic fractions of pyrolysates of Araucaria species. The mass spectra of 5b, 5c, 5d and 5e are given in Fig. 5. The mass spectra of $8 \mathrm{a}$ and $8 \mathrm{c}$ are given in Fig. 8. The mass spectra of 9b, 9c, 9d, 9e, 9f and $9 \mathrm{~g}$ are given in Fig. 9. tr: in trace; $x$ : absence of compound.

Other tricyclic diterpenoids, like abietane-type compounds, show a higher diversity, especially in the aromatic fraction. Related aromatic compounds are retene, dehydroabietane, 18- and 19-norabieta-8, 11, 13-trienes, tetrahydroretene, simonellite, bisnor-simonellite, 2- and 9methylretenes. While the saturated abietane-type compounds like abietanes and fichetelite/norabietanes are detected at trace level.

These abietane-type compounds are the major diterpenoids of Araucaria. They are mostly derived from dehydroabietic acid that is observed in the polar fraction of pyrolysates and more generally from abietanoic acids in the fresh plants. Regarding the phenolic abietanes including sugiol, hinokiol and ferruginol (Otto and Wilde, 2001; Otto and Simoneit, 2001), which are known as abietane-type compounds precursors for Araucariaceae as well, show a low relative abundance in the fresh plants and are mostly degraded during pyrolysis.

A peak having a similar spectrum to those of methylretenes is observed in the aromatic fractions of all Araucaria species (Fig. 8c). Compared to Alexander et al. (1995), the spectra of these compounds have the same molecular ion and mass fragments, but are different by the fragment intensities.
They may rather be consistent with a pentamethyl phenanthrene.

\section{Tetracyclic diterpenoids}

Tetracyclic diterpenoids, mainly ent-beyerane, $16 \alpha(\mathrm{H})$ - and $16 \beta(\mathrm{H})$-phyllocladanes and ent-16 $(\mathrm{H})$ - and ent-16 $\beta(\mathrm{H})-$ kauranes, show relatively high abundance in each representative. They are identified according to the spectra published by Noble et al. (1985). Their spectra are all characterized by a molecular ion at $m / z 274$ and a base peak at $m / z 123$ $\left(\mathrm{C}_{20} \mathrm{H}_{34}\right)$. Distribution and abundance of these compounds for each representative are given in Fig. 6 and Table 2. They are probably derived mainly from beyerene, ent-kaurene, isokaurene and phylloclade-16-ene, as well as kauran-16-ol, phyllocladanol and kaur-16-en-19-ol, detected in the fresh plants. Furthermore, beyerane-type compounds are detected in A. araucana, A. bidwillii and A. cunninghamii in both their fresh plant (beyerene) and the pyrolysates (ent-beyerane). Co-occurrence of phyllocladane-type and kaurane-type compounds is observed in most of Araucaria species, except of A. angustifolia and A. nemorosa. Only phyllocladane-type or kaurane-type compounds are observed in A. angustifolia and in A. nemorosa respectively. 

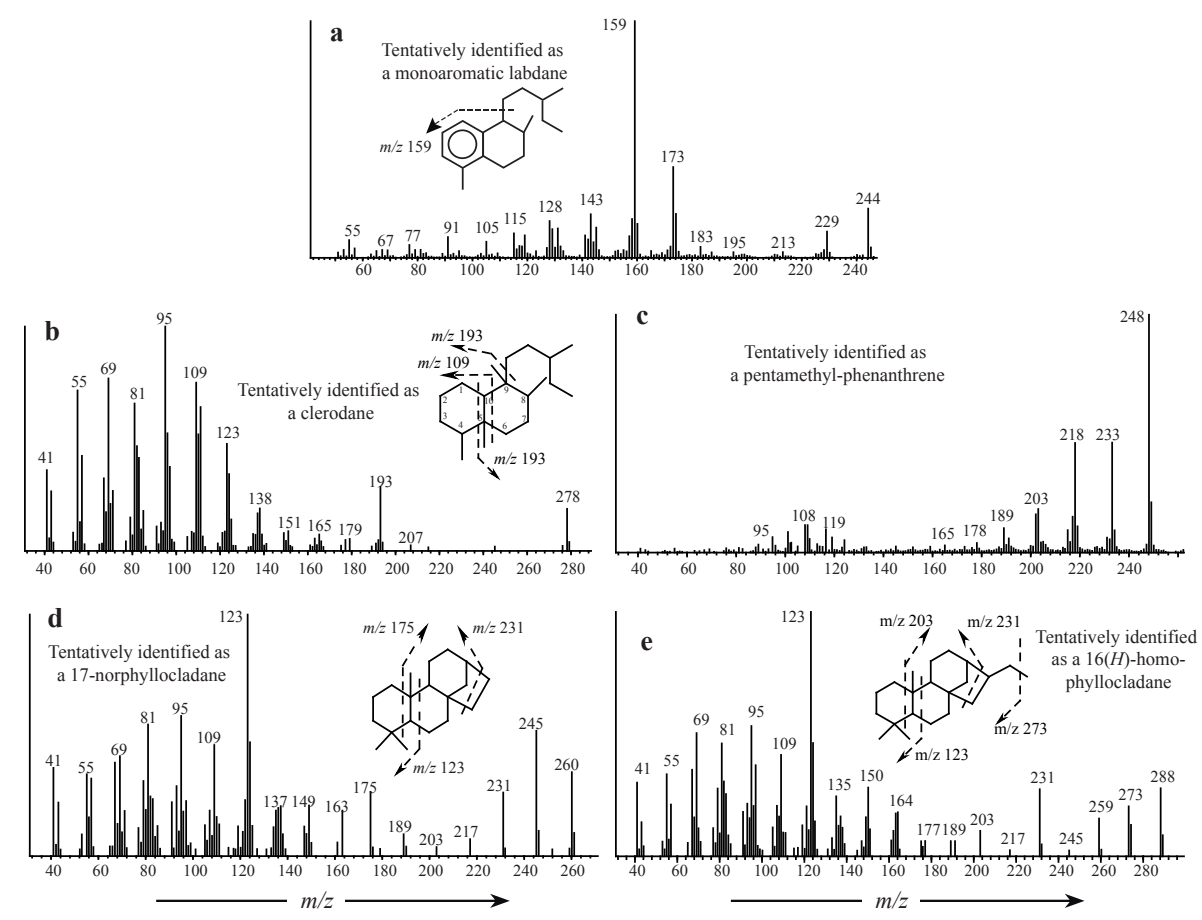

Fig. 8. Mass spectra of some tentatively identified Araucariaceae diterpenoids and suggested mass spectral cleavage patterns for (a), (b), (d) and (e). (a): monoaromatic labdane; (b): clerodane; (c): pentamethyl-phenanthrene; (d): 17-norphyllocladane (identified according to Noble et al., 1986); (e): 16(H)-homo-phyllocladane.

A peak with a spectrum characterized by a molecular ion at $m / z 260\left(\mathrm{C}_{19} \mathrm{H}_{32}\right)$ with a base peak at $m / z 123$ is detected in A. angustifolia. This spectrum matches very well to that of 17-nortetracyclic diterpane described by Noble et al. (1986) (Fig. 8d). Formation of this C-19 diterpane is likely due to the demethylation of a C-20 tetracyclic diterpane, while its precise molecular structure remains unclear. Furthermore, in the case of A. angustifolia, as only phyllocladanes are observed, the C-19 tetracyclic diterpane could rather be a 17norphyllocladane.

Another peak, characterized by a molecular ion at $m / z 288$ $\left(\mathrm{C}_{21} \mathrm{H}_{32}\right)$ and a base peak at $m / z, 123$ is detected in A. angustifolia, A. bernieri and A. laubenfelsii (Fig. 8e). It is likely a methylated tetracyclic diterpane because the positive difference of molecular weight of $14 \mathrm{Da}$ to the well-known tetracyclic diterpenoids corresponds to an additional $\mathrm{CH}_{2}$ group. This configuration is in correspondence to a C-21 tetracyclic diterpane. Moreover, (1) according to the spectrum, the ion at $m / z 231$ is relatively more abundant than the ions at $m / z 259$; (2) A. angustifolia, A. bernieri and A. laubenfelsii all show the presence of phyllocladanes. This C-21 tetracyclic diterpane is probably a $16(\mathrm{H})$-homo-phyllocladane.

It is also interesting to point out that, according to Otto and Wilde (2001), tetracyclic diterpenoids like trachylobanetype and atiserane-type compounds are those exclusive to the Araucaria genus among all conifers. Unfortunately, the diagenetic products of these two compounds are, to our knowledge, still unknown. In our study, trachylobane and atiserene/isoatiserene are identified in the fresh A. araucana and $A$. nemorosa, yet no possible corresponding pyrolysates could be identified.

\section{Unidentified compounds}

Numerous compounds remain unidentified in the extract of Araucaria pyrolysates and some of them, their mass spectra are given in the Figs. 5d, 5e and 9a-h. Tentative identification as proposed in Fig. 9a suggests saturated tricyclic diterpenoid. They have, to our knowledge, never been reported in previous studies on vascular plant biomarkers. Nevertheless, many of them are quite abundant in several species. For instance, it was observed that two peaks having spectra with molecular ions at $m / z 238$ $\left(\mathrm{C}_{18} \mathrm{H}_{22}\right.$; Fig. 5d) and $254\left(\mathrm{C}_{19} \mathrm{H}_{26} ;\right.$ Fig. 5e), base peaks at $\mathrm{m} / z, 168$ and 184 , respectively, co-appear with 2,6-dimethyl1-(4-methylpentyl)naphthalene and 6-ethyl-2-dimethyl-1-(4methylpentyl)-naphthalene. These two unidentified peaks show also respectively similar abundance to 2,6-dimethyl1-(4-methylpentyl)naphthalene and 6-ethyl-2-dimethyl-1-(4methylpentyl)-naphthalene. The relationship of the compounds is not clear; while their co-occurrence and similar fragmentation tend each couple to a similar structure. However, these unidentified compounds may have some relevant 


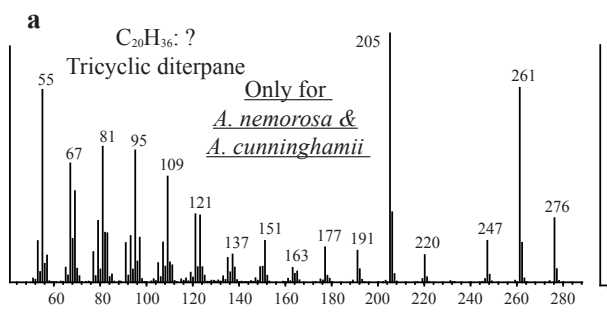

b
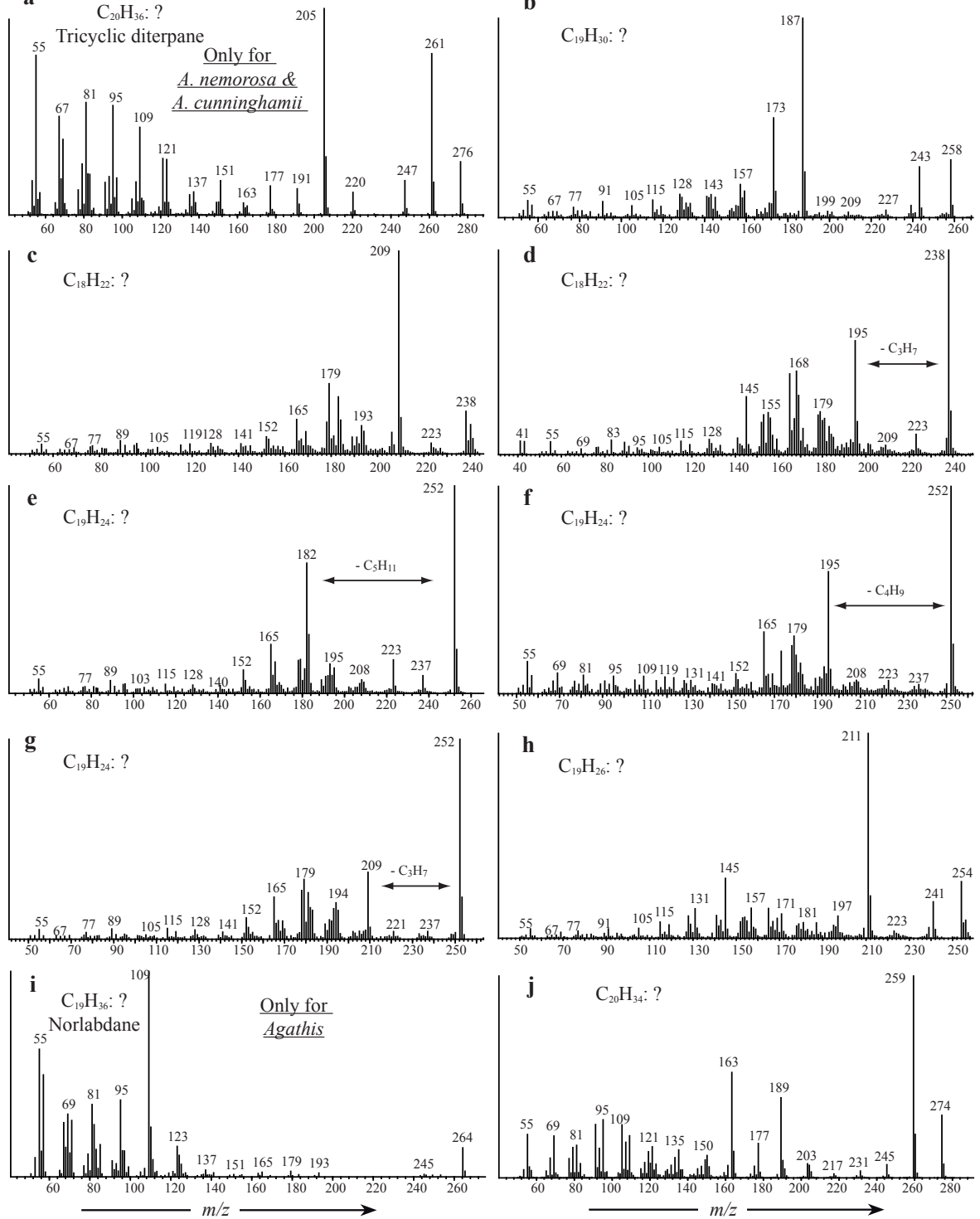

Fig. 9. Mass spectra of some unidentified, but recurrent Araucariaceae diterpenoids. (a) (only for A. nemorosa and A. cunninghamii in Fig. 6), (i-j) (only for Agathis, in Fig. 11): in the aliphatic fraction; (b-g) in the aromatic fraction (Figs. 6 and 11).

palaeochemotaxonomic values, and special attention should be paid to these biomarkers in future studies.

Relative abundance of major class of Araucaria diterpenoids (including saturated and aromatic compounds) in each representative is summarized in Table 4.

\subsection{Molecular characteristics of artificially diagenetic Agathis genus}

\subsubsection{Sesquiterpenoids}

The composition of sesquiterpenoids in Agathis (Ag.) species is shown in Figs. 10 (saturated) and 11 (aromatic). The proportion of each sesquiterpenoid is given in Table 2 (saturated) and Table 3 (aromatic). Some similari- ties to the molecular composition of Araucaria species are observed. Farnesane, cadalane-type compounds (saturated cadalanes, calamene, calamenene, cadalene and norcadalene), pentamethyl-dihydroindenes and chamazulene show some high relative abundances in each Agathis representative. 1,3,4-trimethyl-2-(4-methylpentyl)benzene is detected as well, but at trace level.

Furthermore, bisabolane-type compounds (bisabolanes and dihydro-ar-curcumene), which are widespread in Araucaria genus, are observed only in Ag. australis and show a low abundance in the other Agathis species. Concerning the eudesmanes, they are detected only in Ag. australis. 
Aliphatic sesquiterpenoids

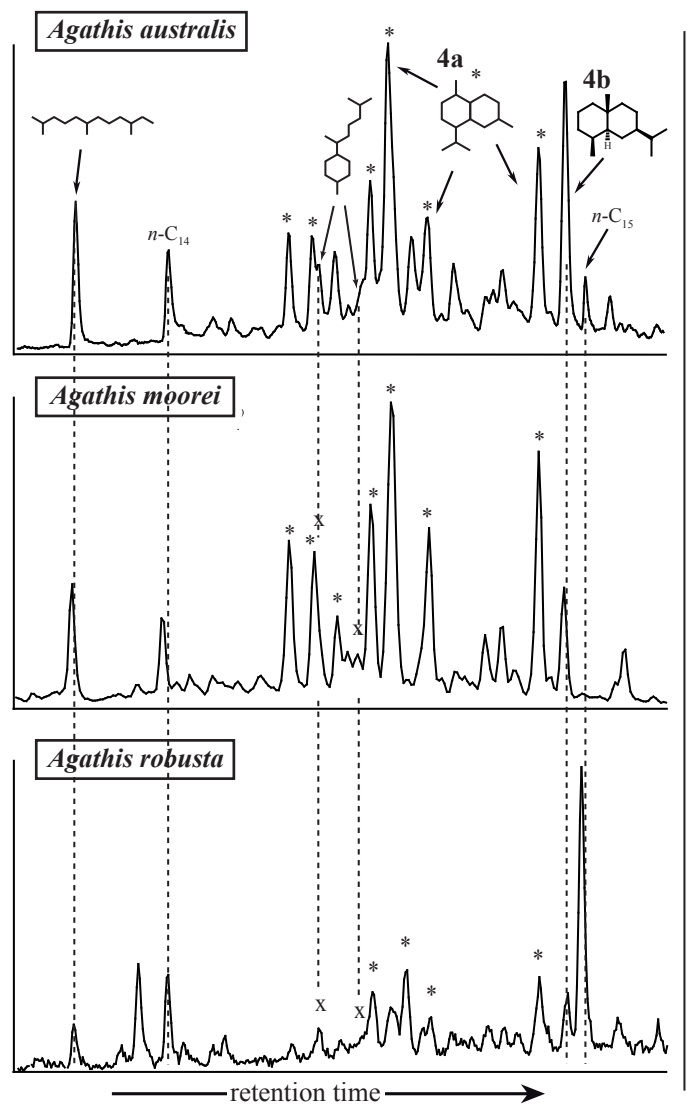

Aromatic sesquiterpenoids

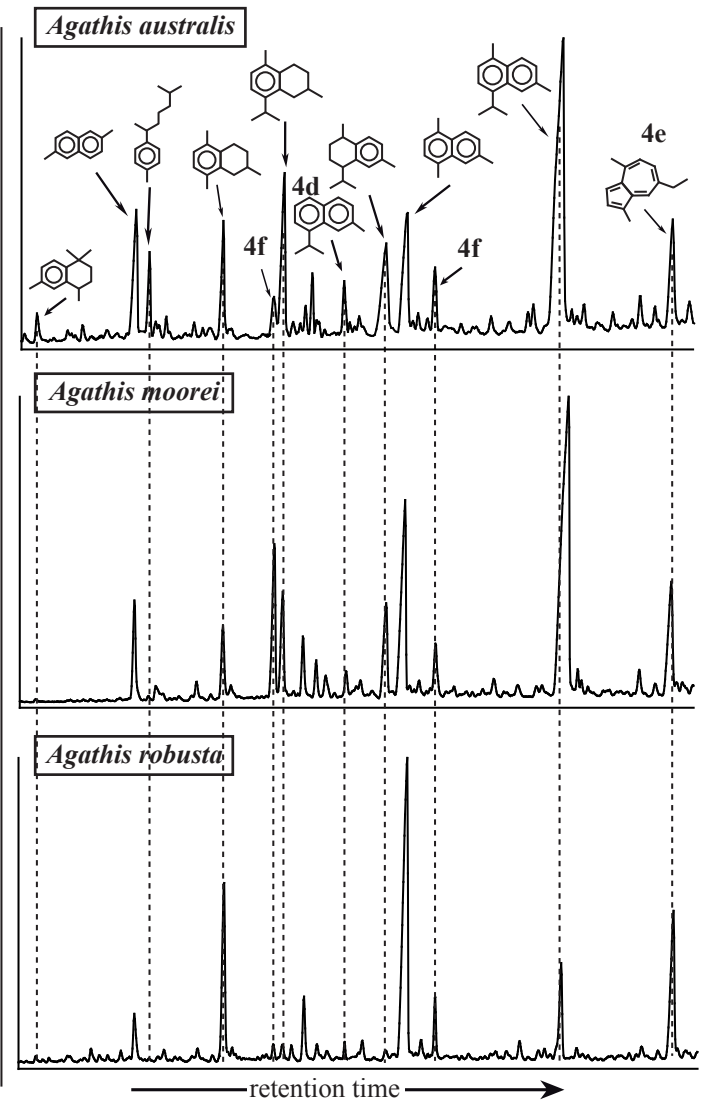

Fig. 10. Partial chromatograms (sesquiterpenoids retention time windows) of aliphatic (left) and aromatic (right) fractions of pyrolysates of Agathis species. The mass spectra of $4 \mathrm{a}, 4 \mathrm{~b}, 4 \mathrm{e}, 4 \mathrm{f}$ and $4 \mathrm{f}$ are given in Fig. 4. $x$ : absence of compound ; ${ }^{*}$ : cadalane-type compounds.

\subsubsection{Diterpenoids}

As sesquiterpenoids, compositions of diterpenoids of Agathis species (Fig. 11) show also several similarities to those of Araucaria. Distribution and abundance of major diterpenoids of the Agathis genus are given in Tables 2 and 3.

Bicyclic diterpenoids are characterized by the presence of labdanes in the aliphatic fraction and monoaromatic labdane in the aromatic fraction, which essentially originate from agathic acids (Thomas, 1969). The tricyclic diterpenoids like isopimarane is observed in Ag. australis and Ag. robusta. Isohexyl alkylaromatic hydrocarbons (2,6-dimethyl1-(4-methylpentyl)naphthalene and 6-ethyl-2-dimethyl-1-(4methylpentyl)-naphthalene) show high relative abundance in most Agathis species and are found as traces for Ag. robusta (Fig. 5b and c). Abietane-type compounds show a high abundance in all species. Aromatic abietanes, like retene, dehydroabietane, 18- and 19-norabieta-8,11,13-trienes, tetrahydroretene, 2- and 9-methylretenes, are much more abundant in Ag. moorei and Ag. robusta than in Ag. australis. Methylretenes and norabieta-8,11,13-trienes are detected only at trace level in Ag. australis. Saturated abietanes are gener- ally in trace in Ag. australis and Ag. moorei, but in higher abundance in Ag. robusta. As for Araucaria, the detected abietane-type compounds are in majority derived from dehydroabietic acid (detected in the pyrolysates) as well as from other abietanoic acid precursors and (cetono)phenolic abietanes (detected in the fresh plants). Only dehydroabietic acid is observed in the pyrolysats. Tetracyclic diterpenoids, ent-beyerane is identified only in Ag. australis; $16 \alpha(\mathrm{H})$ phyllocladane, ent-16 $\alpha(\mathrm{H})$ - and ent-16 $\beta(\mathrm{H})$ - kauranes, are detected in high abundance except for Ag. robusta. Despite the presence and the absence, these tetracyclic compounds represent the major components within the Agathis species. The unidentified compounds, like those of Fig. 8a to 8e, are also detected with significant abundances in Agathis species.

Furthermore, some peaks show relatively high abundance and their spectra are respectively characterized by molecular ions at $m / z 264$ and 274. A base peaks at $m / z 109$ and 259 are observed in the aliphatic fraction of Ag. australis and Ag. moorei. Their chemical formulas are, respectively, $\mathrm{C}_{20} \mathrm{H}_{24}$ and $\mathrm{C}_{20} \mathrm{H}_{34}$, and their spectra are given in Fig. $9 \mathrm{i}$ and $9 \mathrm{j}$. Since these spectra are neither referenced in the literature nor in our spectral database, their molecular structures 
Aliphatic diterpenoids

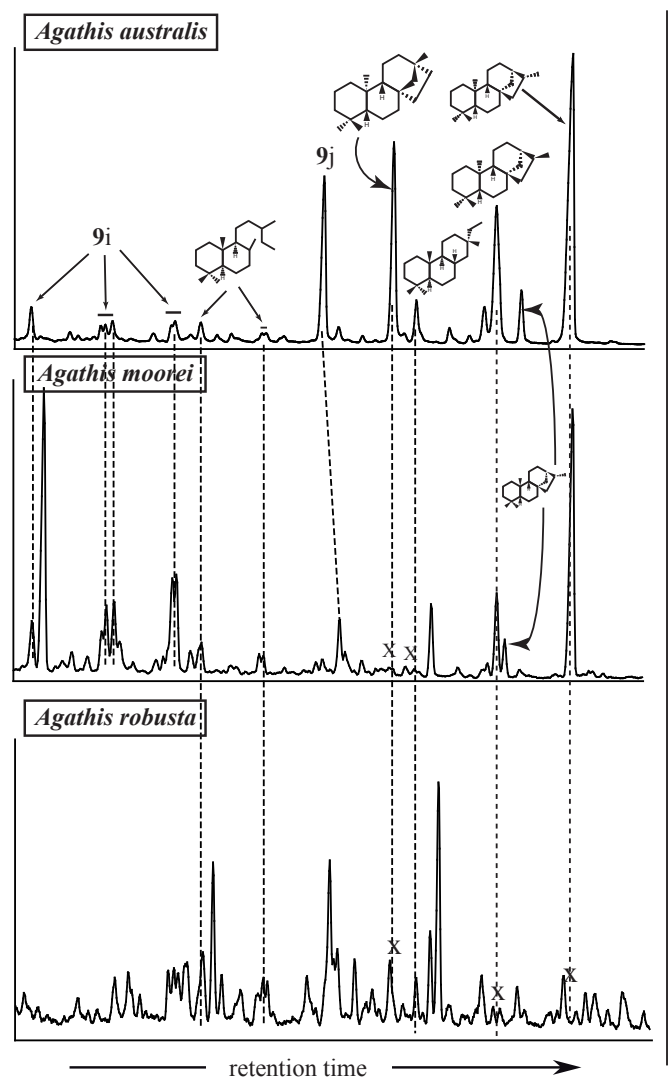

Aromatic diterpenoids

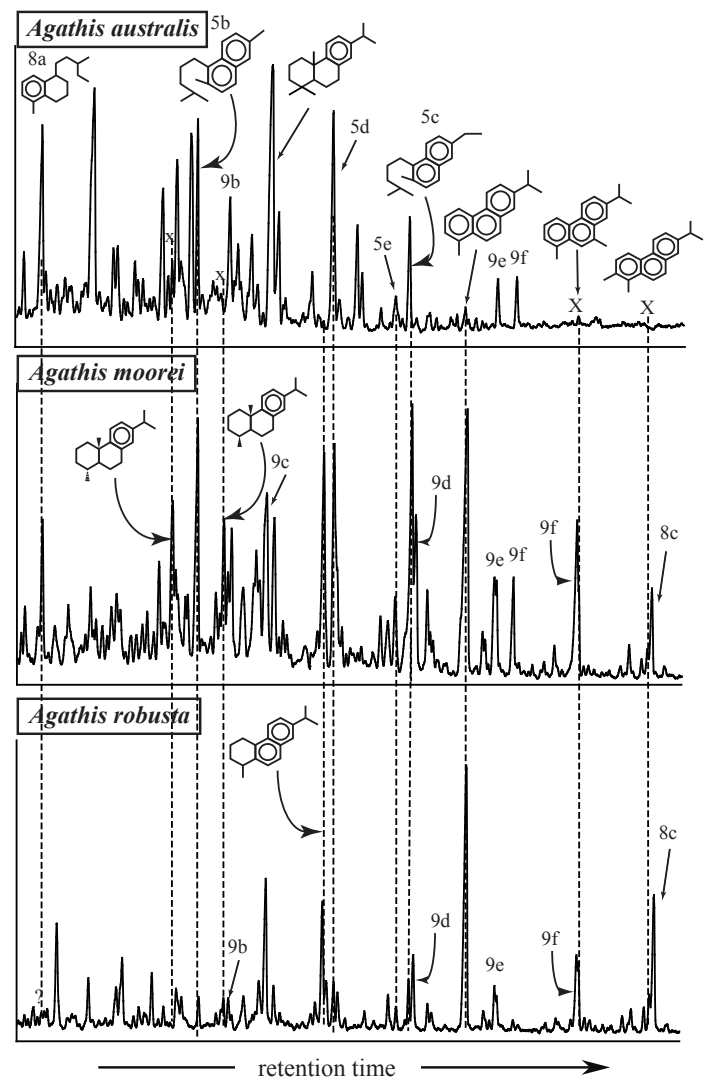

Fig. 11. Partial chromatograms (diterpenoids retention time windows) of aliphatic (left) and aromatic (right) fractions of pyrolysates of Agathis species. The mass spectra of $5 \mathrm{~b}$ to $5 \mathrm{e}$ are given in Fig. 5. The mass spectra of $8 \mathrm{a}$ and $8 \mathrm{c}$ are given in Fig. 8 . The mass spectra of $9 \mathrm{~b}$ to $9 \mathrm{j}$ are given in Fig. 9. $x$ : absence of compound.

are not yet clear. However their frequent, significant and also unique presence (Fig. 9i) and predominance (Fig. 9j) in Agathis species could be interesting for future biomarker research.

In addition, the relative abundance of major class of sesquiterpenoids and diterpenoids in each Agathis representative is summarized in Table 4.

\subsection{Molecular characteristics of artificially diagenetic of Wollemia nobilis}

W. nobilis shows several similarities to other Araucariaceae genera (Figs. 2 and 3, Figs. 6 and 7, as well as Figs. 10 and 11). Relative proportions of sesquiterpenoids and diterpenoids of this monotypic genus are given in Tables 2 and 3.

For the sesquiterpenoids, W. nobilis is characterized by the presence of eudesmane-type $[4 \alpha(\mathrm{H})-$ and $4 \beta(\mathrm{H})$ - eudesmanes], bisabolane-type (bisabolane, ar-curcumene and dihydro-ar-curcumene), cadalane-type (saturated cadalanes, norcadalene, calamene, calamenene and cadalene) compounds. Pentamethyl-dihydroindene in $W$. nobilis is not as abundant as those observed in Araucaria and Agathis species among the sesquiterpenoids. Chamazulene, which presents a relatively high abundance in both Araucaria and Agathis, is here absent.

Furthermore, W. nobilis shows a wide diversity of diterpenoids. On one hand, as the other Araucariaceae species, it is characterized by the presence of labdane-type compounds (like labdanes), isohexyl alkylaromatic hydrocarbons (like 2,6-dimethyl-1-(4-methylpentyl)naphthalene and 6-ethyl-2-dimethyl-1-(4-methylpentyl)-naphthalene), abietane-type compounds (like retene, dehydroabietane, 18- and 19- norabieta-8,11,13-trienes, tetrahydroretene, 2and 9- methylretenes as well as dehydroabietic acid), and tetracyclic diterpenoids (like ent-beyerane, ent-16 $\alpha(\mathrm{H})$ - and ent-16 $\beta(\mathrm{H})$ - kauranes). Phyllocladane-type compounds, being largely widespread in most of Araucariaceae species, are neither detected in fresh nor in pyrolysates of W. nobilis. Moreover, due to the high abundance of tetracyclic diterpenoids, the saturated abietanes are present at trace level in the aliphatic fraction. The unidentified compounds like those cited in Sect. 4.1.2. (Fig. 9) show significant abundances. The diversity of diterpenoids of W. nobilis is, on the other hand, demonstrated by a great variety of other 

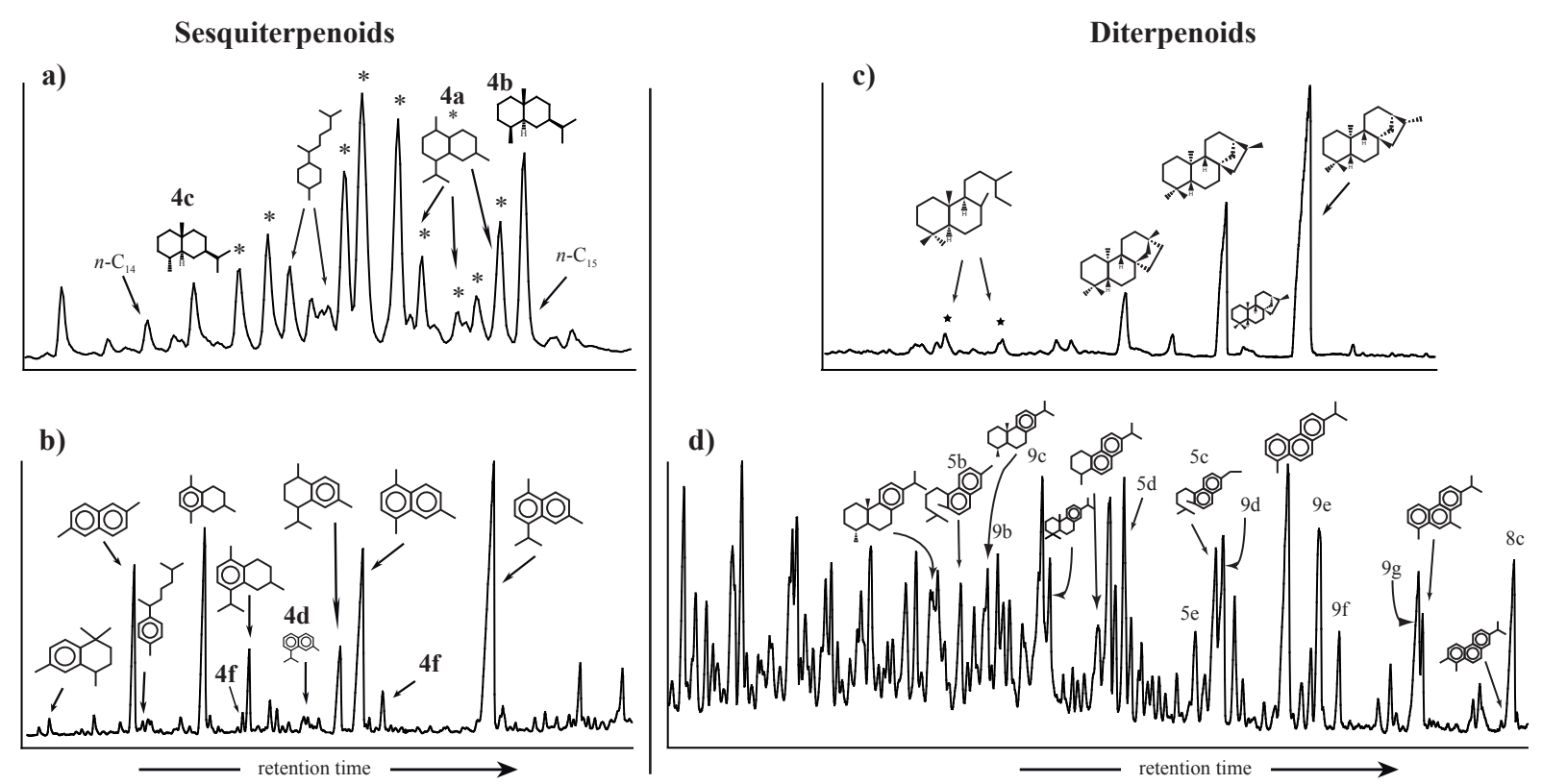

Fig. 12. Partial chromatograms (sesquiterpenoids $(\mathbf{a}, \mathbf{b})$ and diterpenoids $(\mathbf{c}, \mathbf{d})$ retention time windows) of aliphatic (a, c) and aromatic $(\mathbf{b}$, d) fractions of pyrolysates of Wollemia nobilis. The mass spectra of $4 \mathrm{a}, 4 \mathrm{~b}, 4 \mathrm{c}, 4 \mathrm{~d}$ and $4 \mathrm{f}$ are given in Fig. 4 . The mass spectra of $5 \mathrm{~b}$ to $5 \mathrm{e}$ are given in Fig. 5. The mass spectra of $8 \mathrm{c}$ are given in Fig. 8. The mass spectra of $9 \mathrm{~b}$ to $9 \mathrm{f}$ are given in Fig. 9. *: cadalane-type compounds.

unknown aromatic diterpenoids. The particularities of these compounds are that they are of similar abundance with no predominance of any specific compounds (Fig. 12).

Relative abundances of major classes of sesquiterpenoids and diterpenoids in Wollemia nobilis are summarized in Table 4 .

\section{Conclusion}

Palaeochemotaxonomy of the Araucariaceae family is evaluated using artificial maturation by confined pyrolysis of extant species. The Araucariaceae family is characterized by the remarkable predominance of saturated tetracyclic diterpenoids, including beyerane, phyllocladanes as well as kauranes. This family is also characterized by a relatively high abundance of sesquiterpenoids (like cadalanes, bisabolane, eudesmane as well as chamazulene) and diterpenoids (like abietanes). The palaeochemotaxonomy of the Araucariaceae could be summarized as follows:

- the Araucaria genus is mainly characterized by the high abundance of sesquiterpenoids, like eudesmanes, bisabolanes, chamazulene, pentamethyl-dihydroindenes and more particularly by cadalane-type compounds. For the diterpenoids, saturated tetracyclic compounds are largely predominant. Compared to the tetracyclic diterpenoids, other diterpenoids, like labdane, isopimarane, abietanes as well as isohexyl alkylaromatic hydrocarbons, show a relatively lower abundance. Moreover, isopimarane is only detected in the Eutecta section species.

- the Agathis genus is characterized by the high abundance of sesquiterpenoids, like cadalane-type compounds, chamazulene and pentamethyl-dihydroindenes. Compared to the Araucaria genus, bisabolanes and eudesmanes are occasionally present in only some species. Concerning the diterpenoids, most species are highly similar to those of Araucaria species, which are characterized by a high abundance of tetracyclic diterpanes and isohexyl alkylaromatic hydrocarbons, but a low abundance of saturated abietanes. This is the case for Ag. australis and Ag. moorei, but not for Ag. robusta. The latter is characterized by the absence of tetracyclic diterpane and a relatively lower abundance of isohexyl alkylaromatic hydrocarbons. The saturated abietanes represent thus a significant fraction of the aliphatics. Moreover, the aromatic abietanes show constantly a high relative abundance in all Agathis representatives.

- Wollemia nobilis presents high similarities to Araucaria genus. Presence of cadalane-types, bisabolanes, eudesmanes, pentamethyl-dihydroindenes and also the absence of chamazulene characterize the sesquiterpenoids signature of Wollemia nobilis. Tetracyclic compounds, like ent-beyerane and ent-kauranes, are predominant among the diterpenoids. Other recurrent diterpenoids in Araucaria and Agathis genera, like labdanes and isopimarane, are at trace amount or absent. The recurrent abietane-type compounds are identified. The aromatic 
abietanes do not seem as abundant as those observed in the two other genera. In addition, Wollemia nobilis shows a great variety of unidentified aromatic diterpenoids and they are of the similar relative abundance as much of the other well-known biomarkers like the aromatic abietane-type compounds and the isohexyl alkylaromatic hydrocarbons.

Acknowledgements. We thank Alain Rouiller, Fredéric Lannuzel, Bastien Farre for technical assistance. We thank Frederic Thévenard (UMR 5276 LGLTPE, University Claude Bernard, Lyon I), Anne Allaria (Botanical Garden of the Villa Thuret, INRA, Antibes), Denis Larpin (Museum Nationale d'Histoire Naturelle, Paris), Romaric Pierrel and Marc Rémy (Botanical Garden of Montet, Vandoeuvre-lès-Nancy) for their help for providing samples. We also thank the Wollemi Pine France (http://france.wollemipine.com) and the Kientzler society for providing branches of the Wollemi Pine in 2006 during the propagation programme of this species in several botanical gardens around the world. We also wish to thank the handling editor of Biogeoscience (X. Wang), Dr. Sawada and a second anonymous reviewer for their appreciation, as well as for their numerous helpful suggestions, which improved the quality of our manuscript. This research benefited from the support of the Ministry of Higher Education and Research of France (MESR) through a PhD grant to Yueming Lu.

Edited by: X. Wang

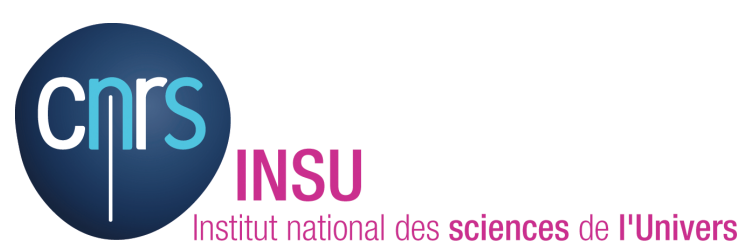

The publication of this article is financed by CNRS-INSU.

\section{References}

Achari, R. G., Shaw, G., and Holleyhead, R.: Identification of ionene and other carotenoid degradation products from the pyrolysis of sporopollenins derived from some pollen exines, a spore coal and the Green River shale, Chem. Geol., 12, 229-234, 1973.

Alexander, R., Kagi, R., and Noble, R.: Identification of the bicyclic sesquiterpenes drimane and eudesmane in petroleum, J. Chem. Soc. Chem. Comm., 5, 226-228, 1983.

Alexander, R., Bastow, T. P., Fisher, S. J., and Kagi, R. I.: Geosynthesis of organic compounds: II. Methylation of phenanthrene and alkylphenanthrenes, Geochim. Cosmochim. Ac., 59, 42594266, 1995.

Aplin, T. T., Cambie, R. C., and Rutledge, P. S.: The taxonomic distribution of some diterpene hydrocarbons, Phytochemistry 2, 205-214, 1963.

Axsmith, B. J., Krings, M., and Waselkov, K.: Conifer pollen cones from the Cretaceous of Arkansas: implications for diversity and reproduction in the Cheirolepidiaceae, J. Paleontol., 78, 402409, 2004.

Brophy, J. J., Goldsack, R. J., Wu, M. Z., Fookes, C. J. R., and Forster, P. I.: The steam volatile oil of Wollemia nobilis and its comparison with other members of the Araucariaceae (Agathis and Araucaria), Biochem. Syst. Ecol., 28, 563-578, 2000.

Caputo, R. and Mangoni, L.: Diterpenes from Araucaria bidwilli, Phytochemistry, 13, 467-470, 1974.

Caputo, R., Dovinola, V., and Mangoni, L.: New diterpenes from Araucaria cunninghami, Phytochemistry, 13, 475-478, 1974a.

Caputo, R., Dovinola, V., and Mangoni, L.: New labdane diterpenes from Araucaria cooki, Phytochemistry 13, 471-474, 1974b.

Caputo, R., Mangoni, L., Monaco, P., Pelosi, L., and Previtera, L.: Neutral diterpenes from Araucaria bidwilli, Phytochemistry, 15, 1401-1402, 1976.

Castro, M. A., Gordaliza, M., Miguel Del Corral, J. M., and Feliciano, A. S.: The distribution of lignanoids in the order coniferae, Phytochemistry, 41, 995-1011, 1996.

Colombini, M. P., Giachi, G., Modugno, F., and Ribechini, E.: Characterisation of organic residues in pottery vessels of the Roman age from Antinoe (Egypt), Microchem. J., 79, 83-90, 2005.

Cox, R. E., Yamamoto, S., Otto, A., and Simoneit, B. R. T.: Oxygenated di- and tricyclic diterpenoids of southern hemisphere conifers, Biochem. Syst. Ecol., 35, 342-362, 2007.

de Paiva Campello, J. and Fonseca, S. F.: Diterpenes from Araucaria angustifolia, Phytochemistry, 14, 2299-2300, 1975.

Dettmann, M. E. and Clifford, H. T.: Biogeography of Araucariaceae, Australia and New Zealand Forest Histories: No. 2, in: Araucarian Forests, edited by: Dargavel, J., 2, 2005.

Dutta, S., Mallick, M., Kumar, K., Mann, U., and Greenwood, P. F.: Terpenoid composition and botanical affinity of Cretaceous resins from India and Myanmar, Int. J. Coal Geol., 85, 49-55, 2011.

Ellis, L., Singh, R. K., Alexander, R., and Kagi, R. I.: Formation of isohexyl alkylaromatic hydrocarbons from aromatizationrearrangement of terpenoids in the sedimentary environment: A new class of biomarker, Geochim. Cosmochim. Ac., 60, 47474763, 1996.

Enright, N. and Hill, R.: The southern conifers: an introduction, in: Ecology of the Southern Conifers, edited by: Enright, N. and Hill, R., Melbourne University Press, Melbourne, 1-9, 1995.

Farella, N., Lucotte, M., Louchouarn, P., and Roulet, M.: Deforestation modifying terrestrial organic transport in the Rio Tapajos, Brazilian Amazon, Org. Geochem., 32, 1443-1458, 2001.

Gupta, N. S., Michels, R., Briggs, D. E. G., Evershed, R. P., and Pancost, R. D.: The organic preservation of fossil arthropods: an experimental study, P. Roy. Soc. B Biol. Sci., 273, 2777-2783, 2006.

Gupta, N. S., Michels, R., Briggs, D. E. G., Collinson, M. E., Evershed, R. P., and Pancost, R. D.: Experimental evidence for the formation of geomacromolecules from plant leaf lipids, Org. Geochem., 38, 28-36, 2007.

Hautevelle, Y., Michels, R., Malartre, F., and Trouiller, A.: Vascular plant biomarkers as proxies for palaeoflora and palaeoclimatic changes at the Dogger/Malm transition of the Paris Basin (France), Org. Geochem., 37, 610-625, 2006a.

Hautevelle, Y., Michels, R., Lannuzel, F., Malartre, F., and Trouiller, A.: Confined pyrolysis of extant land plants: A contribution to palaeochemotaxonomy, Org. Geochem., 37, 1546-1561, $2006 \mathrm{~b}$. 
Heim, A., Hofmann, A., and Schmidt, M. W. I.: Forest-derived lignin biomarkers in an Australian oxisol decrease substantially after 90 years of pasture, Org. Geochem., 41, 1219-1224, 2010.

Hill, R. S. and Bigwood, A. J.: Tertiary gymnosperms from Tasmania: Araucariaceae, Alcheringa 11, 325-335, 1987.

Huang, Z. Q., Davis, M. R., Condron, L. M., and Clinton, P. W.: Soil carbon pools, plant biomarkers and mean carbon residence time after afforestation of grassland with three tree species, Soil Biol. Biochem., 43, 1341-1349, 2011.

Jaffré, T.: Distribution and ecology of the conifers of New Caledonia, in: Ecology of the Southern Conifers, edited by: Enright, N. J. and Hill, R. S., Cambridge University Press, Cambridge, 171-196, 1995.

Jones, W. G., Hill, K. D., and Allen, J. M.: Wollemia nobilis, a new living Australian genus and species in the Araucariaceae, Telopea, 6, 173-176, 1995.

Jussieu, A. L. D.: Genera plantarum secundum ordines naturales disposita, iuxta methodum in Horto regio Parisiensi exaratam anno 1774, L'Herissant, Paris, 1978.

Kershaw, P. and Wagstaff, B.: The southern conifer family Araucariaceae: History, status, and value for paleoenvironmental reconstruction, Annu. Rev. Ecol. Syst., 32, 397-414, 2001.

Krassilov, V. A.: Araucariaceae as indicators of climate and paleolatitudes, Rev. Palaeobot. Palynolo., 26, 113-124, 1978.

Kunzmann, L.: Neue Untersuchungen zu Araucaria Jussieu aus der europäischen Kreide, Palaeontogr. Abt. B, 276, 97-131, 2007a.

Kunzmann, L.: Araucariaceae (Pinopsida): Aspects in palaeobiogeography and palaeobiodiversity in the Mesozoic, Zool. Anz., 246, 257-277, 2007b.

Lavrieux, M., Jacob, J., LeMilbeau, C., Zocatelli, R., Masuda, K., Bréheret, J.-G., and Disnar, J.-R.: Occurrence of triterpenyl acetates in soil and their potential as chemotaxonomical markers of Asteraceae, Org. Geochem., 42, 1315-1323, 2011.

Leeming, R. and Nichols, P. D.: Determination of the sources and distribution of sewage and pulp-fibre-derived pollution in the Derwent Estuary, Tasmania, using sterol biomarkers, Mar. Freshwater Res., 49, 7-17, 1998.

Mongrand, S., Badoc, A., Patouille, B., Lacomblez, C., Chavent, M., Cassagne, C., and Bessoule, J.-J.: Taxonomy of gymnospermae : multivariate analyses of leaf fatty acid composition, Phytochemistry, 58, 101-115, 2001.

Noble, R. A., Alexander, R., Kagi, R. I., and Knox, J.: Tetracyclic diterpenoid hydrocarbons in some Australian coals, sediments and crude oils, Geochim. Cosmochim. Ac., 49, 21412147, 1985.

Noble, R. A., Alexander, R., Kagi, R. I., and Nox, J. K.: Identification of some diterpenoid hydrocarbons in petroleum, Org. Geochem., 10, 825-829, 1986.

Olawore, N. O.: Analysis of the leaf oil of Araucaria cunninghamii sweet, Grown in Nigeria, The J. Essent. Oil Res., 17, 459-461, 2005.

Otto, A. and Simoneit, B. R. T.: Chemosystematics and diagenesis of terpenoids in fossil conifer species and sediment from the Eocene Zeitz formation, Saxony, Germany, Geochim. Cosmochim. Ac., 65, 3505-3527, 2001.

Otto, A. and Wilde, V.: Sesqui-, di-, and triterpenoids as chemosystematic markers in extant conifers - A review, Bot. Rev., 67, 141$238,2001$.
Otto, A., Simoneit, B. R. T., and Rember, W. C.: Conifer and angiosperm biomarkers in clay sediments and fossil plants from the Miocene Clarkia Formation, Idaho, USA, Org. Geochem., 36, 907-922, 2005.

Pietsch, M. and König, W. A.: Enantiomers of sesquiterpene and diterpene hydrocarbons in Araucaria species, Phytochem. Analysis, 11, 99-105, 2000.

Romanus, K., Van Neer, W., Marinova, E., Verbeke, K., Luypaerts, A., Accardo, S., Hermans, I., Jacobs, P., De Vos, D., and Waelkens, M.: Brassicaceae seed oil identified as illuminant in Nilotic shells from a first millennium AD Coptic church in Bawit, Egypt, Anal. Bioanal. Chem., 390, 783-793, 2008.

Salisbury, R. A.: XIV. The Characters of several Genera in the Natural Order of Coniferæ: with Remarks on their Stigmata, and Cotyledons, Transactions of the Linnean Society of London, 8, 308-317, 1807.

Setoguchi, H., Asakawa Osawa, T., Pintaud, J.-C., Jaffre, T., and Veillon, J.-M.: Phylogenetic relationships within Araucariaceae based on rbcL gene sequences, Am. J. Bot., 85, 1507-1516, 1998.

Simoneit, B. R. T., Grimalt, J. O., Wang, T. G., Cox, R. E., Hatcher, P. G., and Nissenbaum, A.: Cyclic terpenoids of contemporary resinous plant detritus and of fossil woods, ambers and coals, Org. Geochem., 10, 877-889, 1986.

Singh, R. K., Alexander, R., and Kagi, R. I.: Identification and occurrence of norcadalenes and related compounds in crude oils and sediments, Org. Geochem., 21, 249-256, 1994.

Smith, P.: The chemotaxonomy of plants, Arnold, London, 1976.

Staniek, A., Muntendam, R., Woerdenbag, H. J., and Kayser, O.: Essential oil constituents derived from different organs of a relictual conifer Wollemia nobilis, Biochem. Syst. Ecol., 38, 131135, 2010.

Stankiewicz, B. A., Briggs, D. E. G., Michels, R., Collinson, M. E., Flannery, M. B., and Evershed, R. P.: Alternative origin of aliphatic polymer in kerogen, Geology, 28, 559-562, doi:10.1130/0091-7613(2000)28<559:aooapi > 2.0.co;2, 2000.

Stockey, R. A.: The Araucariaceae: An evolutionary perspective, Rev. Palaeobot. Palynolo., 37, 133-154, 1982.

Stockey, R.: Mesozoic Araucariaceae: Morphology and systematic relationships, J. Plant Res., 107, 493-502, doi:10.1007/bf02344070, 1994.

Thomas, B. R.: Kauri resins-modern and fossil. In: Eglinton, G., Murphy, M.T.J. (Eds.), Org. Geochem. - Methods and Results, Springer, Berlin, 599-618, 1969.

van Aarssen, B. G. K., Alexander, R., and Kagi, R. I.: Higher plant biomarkers reflect palaeovegetation changes during Jurassic times, Geochim. Cosmochim. Ac., 64, 1417-1424, 2000.

Vliex, M., Hagemann, H. W., and Püttmann, W.: Aromatized arborane/fernane hydrocarbons as molecular indicators of floral changes in Upper Carboniferous/Lower Permian strata of the Saar-Nahe Basin, southwestern Germany, Geochim. Cosmochim. Ac., 58, 4689-4702, 1994.

Wang, L., Lee, F. S. C., Wang, X. R., Yin, Y. F., and Li, J. R.: Chemical characteristics and source implications of petroleum hydrocarbon contaminants in the sediments near major drainage outfalls along the coastal of Laizhou Bay, Bohai Sea, China, Environ. Monit. Assess., 125, 229-237, doi:10.1007/s10661-0069514-0, 2007. 